\title{
Wells Turbine for Wave Energy Conversion: A Review
}

\author{
Ahmed S. Shehata, Qing Xiao, Khalid M. Saqr, Day Alexander
}

NOTICE: this is the author's version of a work that was accepted for publication in the International Journal of Energy Research. Changes resulting from the publishing process, such as final peer review, editing, corrections, structural formatting, and other quality control mechanisms may not be reflected in this document. Changes may have been made to this work since it was submitted for publication. This manuscript was accepted for publishing on 29 May 2016 of the Journal. A definitive version was subsequently published in the International Journal of Energy Research, DOI: 10.1002/er.3583. 
2

Ahmed S. Shehata ${ }^{1,2 *}$, Qing Xiao ${ }^{1}$, Khalid M. Saqr ${ }^{3}$, Day Alexander ${ }^{1}$

1) Department of Naval Architecture, Ocean and Marine Engineering, University of Strathclyde, Glasgow G4 0LZ, UK

2) Marine Engineering Department, College of Engineering and Technology, Arab Academy for Science Technology and Maritime Transport, P.O. 1029, AbuQir, Alexandria, Egypt

3) Mechanical Engineering Department, College of Engineering and Technology, Arab Academy for Science Technology and Maritime Transport, P.O. 1029, AbuQir, Alexandria, Egypt

\section{SUMMARY}

In the past twenty years, the use of wave energy systems has significantly increased, generally depending on the oscillating water column (OWC) concept. Wells turbine is one of the most efficient OWC technologies. This article provides an updated and a comprehensive account of the state of the art research on Wells turbine. Hence, it draws a roadmap for the contemporary challenges which may hinder future reliance on such systems in the renewable energy sector. In particular, the article is concerned with the research directions and methodologies which aim at enhancing the performance and efficiency of Wells turbine. The article also provides a thorough discussion of the use of computational fluid dynamics (CFD) for performance modeling and design optimization of Wells turbine. It is found that a numerical model using the CFD code can be employed successfully to calculate the performance characteristics of $\mathrm{W}-\mathrm{T}$ as well as other experimental and analytical methods. The increase of research papers about CFD, especially in the last five years, indicates that there is a trend that considerably depends on the CFD method.

Keywords: Wells turbine; CFD; Wave energy; Oscillating water column.

\footnotetext{
* Corresponding Author: Ahmed S. Shehata
}

E-mail address: ahmed.mohamed-ahmed-shehata@strath.ac.uk 


\begin{tabular}{|c|c|c|c|}
\hline \multicolumn{4}{|c|}{ Nomenclature } \\
\hline A & The total blade area $=(\mathrm{zc} \mathrm{b}), \mathrm{m}^{2}$ & $R_{m}$ & Mean rotor radius $=\frac{R_{t}+R_{h}}{2}, \mathrm{~m}$ \\
\hline$A_{r}$ & Rotor area $=\pi R_{m}^{2}, \mathrm{~m}^{2}$ & $R_{r}$ & Rotor radius , m \\
\hline $\mathrm{a}$ & Margin distance for the endplate, $\mathrm{m}$ & $R_{t}$ & Rotor radius at tip , $\mathrm{m}$ \\
\hline $\mathrm{b}$ & Blade Span , m & $\mathrm{T}$ & Time period $=1 / f, \sec$ \\
\hline $\mathrm{c}$ & Blade chord , $\mathrm{m}$ & $\mathrm{t}$ & Rotor blade thickness , $\mathrm{m}$ \\
\hline$C_{D}$ & Drag force coefficient $=\frac{D}{\frac{1}{2} \rho\left(V_{r}\right)^{2} A}$ & $T_{L}$ & Loading torque $\mathrm{N} \mathrm{m}$ \\
\hline$C_{L}$ & Lift force coefficient $=\frac{L}{\frac{1}{2} \rho\left(V_{r}\right)^{2} A}$ & TSR & Tip speed ratio $=\frac{\omega R m}{V_{A m}}$ \\
\hline $\mathrm{C}_{\mathrm{P}}$ & Power coefficient & $V_{A}$ & Axial velocity $=V_{A m} \sin \left(\frac{2 \pi t}{T}\right), \mathrm{m} / \mathrm{s}$ \\
\hline$C_{T}$ & Torque coefficient & $V_{A m}$ & Maximum value of axial velocity, $\mathrm{m} / \mathrm{s}$ \\
\hline $\mathrm{D}$ & Drag Force ,N & $V_{r}$ & Resultant air velocity $=\sqrt{V_{A}^{2}(t)+\omega^{2}(t) R_{m}^{2}}, \mathrm{~m} / \mathrm{s}$ \\
\hline$D_{r}$ & Rotor diameter , $\mathrm{m}$ & $W^{*}$ & Output power coefficient \\
\hline$f$ & Wave frequency, $\mathrm{Hz}$ & $X_{i}$ & Inertia coefficient \\
\hline $\mathrm{F}_{\mathrm{A}}$ & Axial Force $=\frac{1}{2} \rho V_{r}^{2} A C_{A}, \mathrm{~N}$ & $X_{L}$ & Loading torque coefficient $=\frac{T_{L}}{\rho \pi R_{m}^{3} V_{A m}^{2}}$ \\
\hline $\mathrm{F}_{\mathrm{t}}$ & Tangential Force $=\frac{1}{2} \rho V_{r}^{2} A C_{t}, \mathrm{~N}$ & $\mathrm{Z}$ & Number of blades \\
\hline g & $\begin{array}{l}\text { Leading edge offsetting of a blade from an } \\
\text { axis , m }\end{array}$ & $\alpha$ & $\begin{array}{l}\text { Angle of attack- the angle between the chord line } \\
\text { and the direction of the fluid velocity ,degree }\end{array}$ \\
\hline I & Moment of inertia , $\mathrm{kg} \mathrm{m}^{2}$ & $\eta$ & Mean turbine efficiency \\
\hline $\mathrm{K}$ & Non-dimensional period & $\rho$ & Air specific density, $\mathrm{kg} / \mathrm{m}^{3}$ \\
\hline $\mathrm{L}$ & lift Force , N & $\sigma$ & Turbine solidity $=\frac{\mathrm{zC}}{2 \pi \mathrm{R}_{\mathrm{m}}}$ \\
\hline$\Delta \mathrm{p}$ & $\begin{array}{l}\text { Pressure difference across } \\
\text { the turbine }=\frac{\mathrm{F}_{\mathrm{A}}}{\text { Area }}, \mathrm{N} / \mathrm{m}^{2}\end{array}$ & $\phi$ & Flow coefficient $=\frac{V_{A m}}{\omega_{a v r} * R_{m}}$ \\
\hline Q & Flow rate through the rotor area, $\mathrm{m}^{3} / \mathrm{sec}$ & $\omega$ & Rotor angular speed , $\mathrm{rad} / \mathrm{sec}$ \\
\hline & Rotor radius at hub , $\mathrm{m}$ & $\begin{array}{l}\bar{\omega}^{*} \\
\text { flow }\end{array}$ & $\begin{array}{l}\text { Non-dimensional angular velocity under irregular } \\
\text { condition }\end{array}$ \\
\hline \multicolumn{4}{|c|}{ List of Abbreviations } \\
\hline $\mathrm{AOP}$ & An Optimized Profile & & \\
\hline AR & Aspect Ratio (the ratio of span to chord) & & \\
\hline
\end{tabular}




\section{CFD Computational Fluid Dynamics}

NACA National Advisory Committee for

Aeronautics

OWC Oscillating Water Column

TC Tip Clearance

W-T Wells Turbine

1

\section{1. Introduction}

Generating renewable energy has been increasing considerably in the past decade,

4 achieving almost 22\% of the global energy production in 2013, compared to 14\% in 2005 [1].

5 The ocean is a potential goldmine for renewable energy generation for several reasons, most

6 important of which is that, unlike wind and solar power, power from ocean waves continues to

7 be produced around the clock [2]. In addition, wave energy varies with the square of wave

8 height, whereas wind energy varies with the cube of air speed. This results in a much higher

9 average power production from waves per unit of time [3]. Moreover, marine waves travel great

10 distances without significant energy losses, so they act as a renewable and an efficient energy

11 transport mechanism across thousands of kilometers. Such renewable energy can be produced

12 through different devices, which produce sufficient work to drive electrical generators that

13 convert such work into electricity. Wave energy extractors can be classified according to the

14 water depth at which they operate. This classification is presented in Figure 1. Another 15 classification based mostly on working principle is presented in Table 1. 


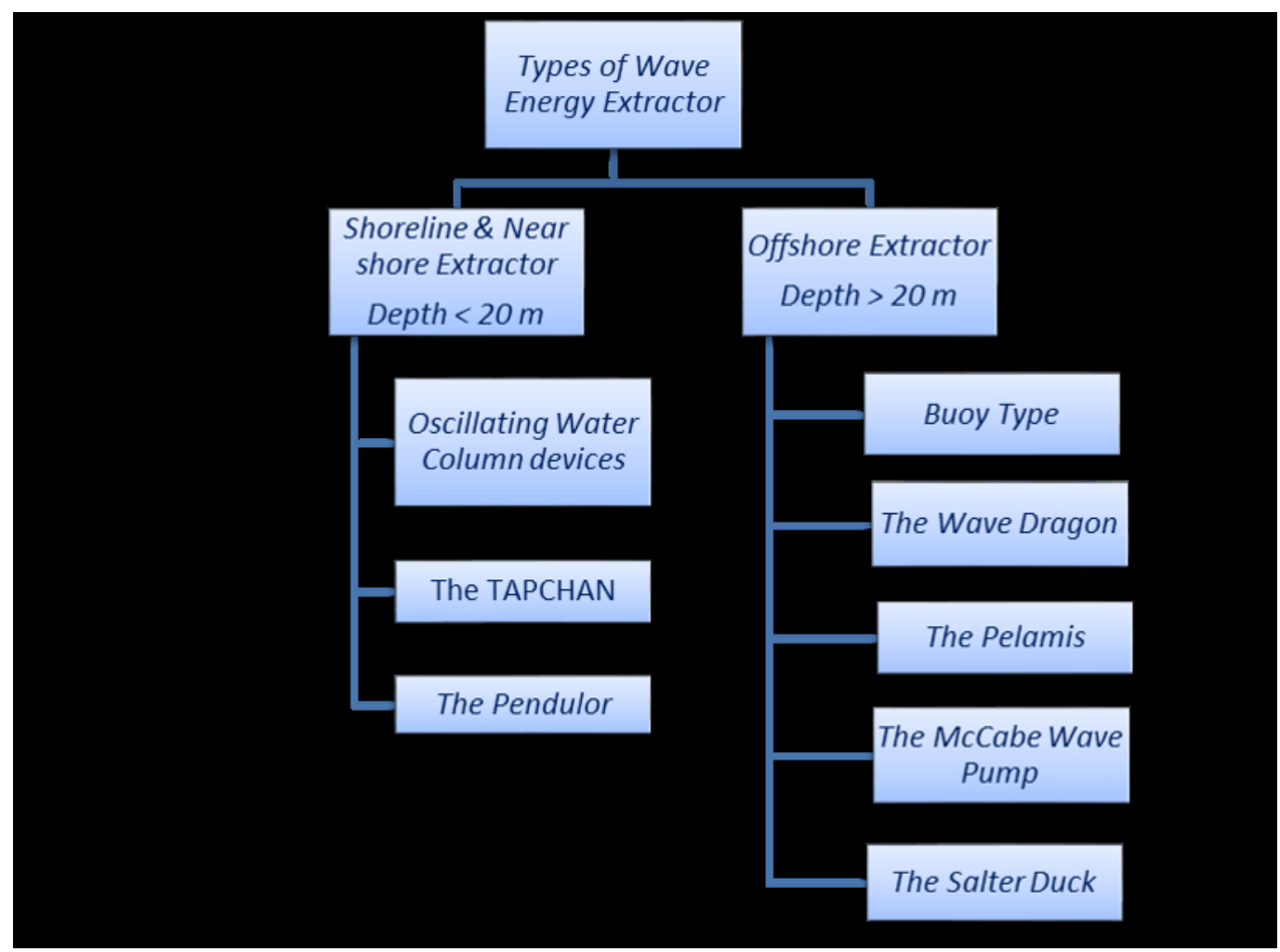

Figure 1 Types of wave energy extractors with respect to water depth

Most of fixed-structure OWC systems are located on the shoreline or near the shore.

4 Shoreline devices are characterized by relatively easier maintenance and installation, and they do not require deep water moorings and long underwater electrical cables. The floating OWC devices are slack-moored to the sea bed and so are largely free to oscillate, enhancing the wave energy absorption if the device is properly designed for that purpose [4]. take advantage of the most powerful wave systems available in deep water. Offshore wave energy converters are in general more complex compared to fixed-structure OWC. This, together with additional problems related to mooring and access for maintenance and the need of long

12 underwater electrical cables, has hindered the converters' development, and only recently have some systems reached, or come close to, the full-scale demonstration stage [5].

Overtopping systems are a different way of converting wave energy to capture the water that is close to the wave crest and introduce it, by over spilling, into a reservoir where it is stored at a level higher than the average free-surface level of the surrounding sea $[6,7]$. The potential energy of the stored water is converted into useful energy through more or less conventional low head hydraulic turbines. The hydrodynamics of overtopping devices is strongly nonlinear, and, 
1 unlike the cases of oscillating body and OWC wave energy converters, cannot be interpreted by

2 linear water wave theory.

Table 1 Types of wave energy extractors based on working principle [6].

\begin{tabular}{|c|c|c|c|c|}
\hline System & Energy extractor & $\begin{array}{l}\text { Structure } \\
\text { types }\end{array}$ & Example & Remarks \\
\hline \multirow{7}{*}{$\begin{array}{c}\text { Oscillating } \\
\text { water column }\end{array}$} & \multirow{7}{*}{ Air turbine } & \multirow{4}{*}{ Fixed structure } & Pico & \multirow{2}{*}{ Isolated } \\
\hline & & & LIMPET & \\
\hline & & & Sakata & \multirow{2}{*}{ Breakwater } \\
\hline & & & Mutriku & \\
\hline & & \multirow{3}{*}{ Floating } & Mighty Whale & \multirow{3}{*}{-------------- } \\
\hline & & & Sperboy & \\
\hline & & & Oceanlinx & \\
\hline \multirow{11}{*}{$\begin{array}{l}\text { Oscillating } \\
\text { bodies }\end{array}$} & \multirow{11}{*}{$\begin{array}{l}\text { Hydraulic motor, } \\
\text { hydraulic turbine and } \\
\text { linear electrical } \\
\text { generator }\end{array}$} & \multirow{8}{*}{ Floating } & AquaBuoy & \multirow{5}{*}{ Essentially translation } \\
\hline & & & IPS Buoy & \\
\hline & & & FO3 & \\
\hline & & & Wavebob & \\
\hline & & & PowerBuoy & \\
\hline & & & Pelamis & \multirow{3}{*}{ Essentially rotation } \\
\hline & & & PS Frog & \\
\hline & & & SEAREV & \\
\hline & & \multirow{3}{*}{ Submerged } & AWS & Essentially translation \\
\hline & & & WaveRoller & \multirow{2}{*}{$\begin{array}{c}\text { Rotation with bottom } \\
\text { hinged }\end{array}$} \\
\hline & & & Oyster & \\
\hline \multirow{3}{*}{ Overtopping } & \multirow{3}{*}{$\begin{array}{c}\text { Low head hydraulic } \\
\text { turbine }\end{array}$} & \multirow{2}{*}{ Fixed structure } & TAPCHAN & Shoreline \\
\hline & & & SSG & Breakwater \\
\hline & & Floating & Wave Dragon & ------- \\
\hline
\end{tabular}

4

5 OWC energy converters operate much like a wind turbine via the principle of wave 6 induced air pressurization [8-10]. A containment housing (air chamber) is placed above the 7 water, allowing the passage of waves to change the water level. The frequently rising and falling 8 water level increases and decreases the air pressure respectively within the housing. With regard 
to this notion, a turbine could be placed on top of the housing through which air may pass. Air 2 would flow into the housing during a wave trough and out of the housing during a wave crest.

3 Such operation principle is illustrated in Figure 2 (a). Because of this bidirectional air flow, the 4 turbine must be designed to rotate only in one direction, regardless of the air flow direction [6, 7 , $511]$.

Finding an efficient and an economical means of converting oscillating flow energy to unidirectional rotary motion for driving electrical generators is the major challenge facing OWC systems. A novel solution for such a challenge is the W-T [12-16], a version of the axial-flow turbine. W-T is named after Professor Alan Wells of the Queen's University of Belfast in the 80 's. It is unique as it contains a rotor with untwisted airfoil blades of symmetrical cross section, usually belonging to the symmetrical NACA four digit series[17-20], see Figure 2 (b). A typical W-T consists of a rotor with about eight airfoil sectioned blades, installed on the hub with their chord lines lying in the plane of rotation. Once the blades have attained design speed, the turbine produces with a fair efficiency a time-averaged positive power output from the oscillating air flow $[4,21]$.

The W-T is one of the simplest and probably the most economical turbines for wave energy conversion. It does not require rectifying air valves and can extract power at a low airflow rate, when other turbines would be inefficient. Therefore, it has been extensively researched and developed in many countries. Most self-rectifying air turbines for wave energy conversion proposed and tested so far are axial-flow machines of two basic types: the W-T and the impulse turbine. The impulse turbine was patented by I. A. Babintsev in 1975 [22]. Its rotor is basically identical to the rotor of a conventional single-stage steam turbine of axial-flow impulse type. Since the turbine is required to be self-rectifying, there are two rows of guide vanes, placed symmetrically on both sides of the rotor, instead of a single row. These two rows of guide vanes are the reflection of each other, with respect to a plane through the rotor disc [2325]. Therefore, it is more complex and more costly than W-T. The efficiency of W-T is higher than that of the impulse turbine when the flow coefficient is less than the stall point. But after the stall point of $\mathrm{W}-\mathrm{T}$, the efficiency of impulse turbine is considerably higher than that of $\mathrm{W}-\mathrm{T}$. However, the peak efficiencies are almost the same [26].

It is worth mentioning that the W-T (with or without guide vanes) and the contra-rotating W-T are approximately a linear turbine (i.e., the pressure drop is approximately proportional to 
1 the flow rate at constant rotational speed). Other turbines behave quite differently (like impulse 2 turbines) [18].The principle of $\mathrm{W}-\mathrm{T}$ is explained in details later in this section.

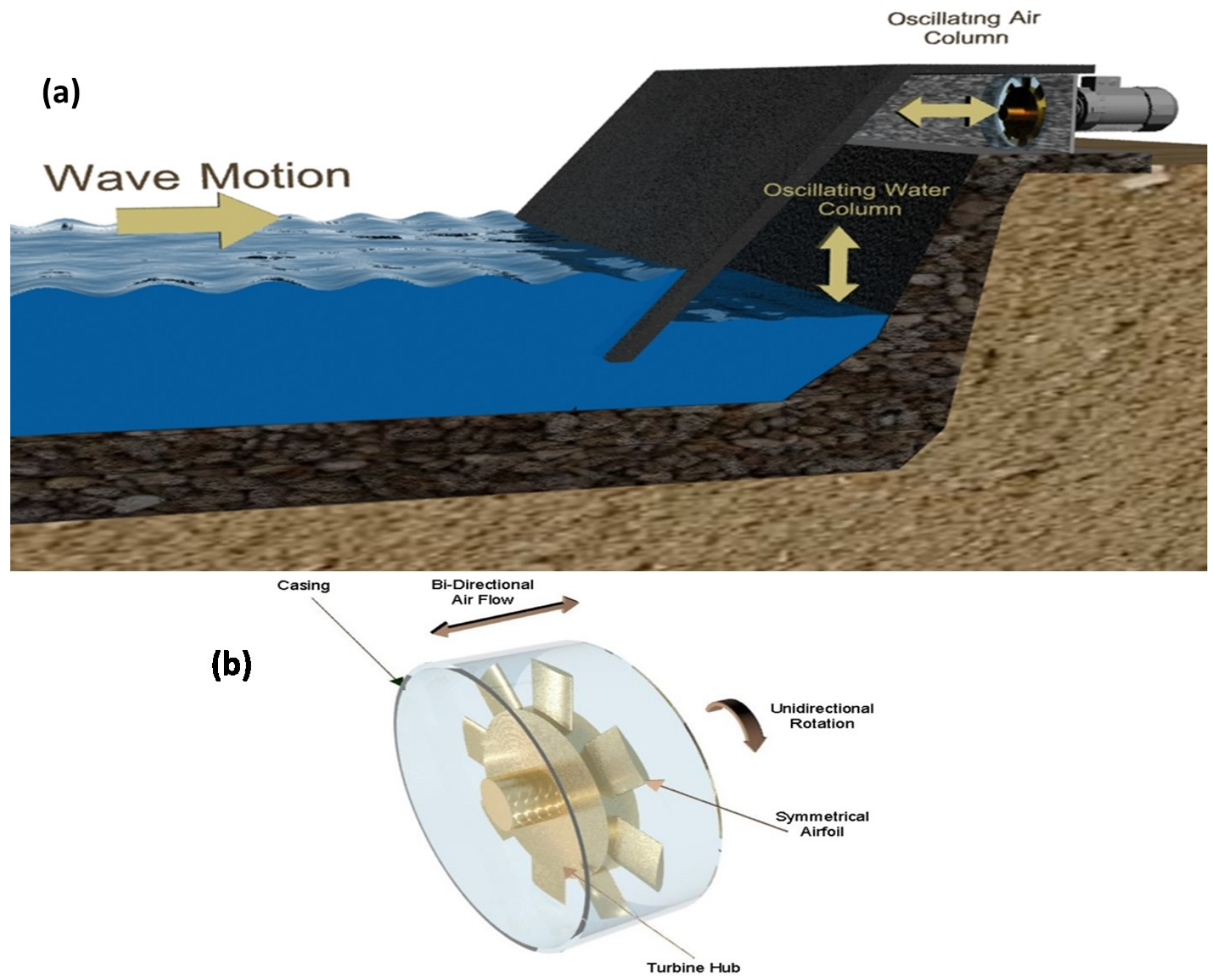

4 Figure 2 OWC energy converters (a) An illustration of the principle of operation of OWC system, where the wave motion is used to drive a turbine through the oscillation of air column[27] (b) Typical structure of W-T rotor[27].

\subsection{Objective, methodology and scope}

The main objective of this review is to provide an updated account, as comprehensive as 11 possible, of the state of the art research on W-T. This article also intends to provide a self12 contained reference for the broadest readership possible within the renewable energy community.

13 The authors have studied all the available research publications related to W-T and conducted a 14 thorough categorization exercise to establish a roadmap for the research directions in the topic. 
This roadmap is based on the W-T system components on the one hand, and on the research approach and methodology of each reference work on the other hand. Therefore, section 1 is dedicated to explain the operation principle, cycle and energy analysis of W-T. A review of existing W-T projects is presented in section 2. Sections 3 and 4 review and discuss the design parameters of $\mathrm{W}-\mathrm{T}$ and the works done to improve their performance through the optimization and modification of such parameters. Since a significant percentage of research utilized CFD to simulate $\mathrm{W}-\mathrm{T}$, section 5 is dedicated to review and discuss these efforts. In section 5 , CFD research works are categorized according to model complexity and physical assumptions. Such categorization, accompanied by a critical discussion of modelling approaches, is intended to highlight the state of the art knowledge for the multidimensional modelling of W-T. Section 6 provides a critical discussion and draws a research roadmap in conclusion of the article.

\subsection{Operation principle of $\mathbf{W}-\mathbf{T}$}

The characteristic feature of W-T is that oscillating air flow produces a single direction determined by three parameters: the camber (first digit), the position of the camber (second digit) and the thickness in percent of the chord (last two digits). Hence, profiles without a camber are symmetrical (NACA 00XX). According to the classical airfoil theory, an airfoil set at $\alpha$ in a fluid flow generates $L$, normal to the free stream. The airfoil also experiences $D$, in the direction of the free stream, see Figure 3 (a) and (b). For real fluids, Lift and Drag increase with the increase in $\alpha$, however only up to a certain value of $\alpha$ beyond which the flow around the airfoil separates. The angle of incidence at which the flow separates from the surface of the airfoil is known as the stall angle [31], see Figure 3 (c). Further increase in $\alpha$ beyond the stall angle results in a decrease in lift and a significant increase in drag [16, 21,29]. Because the flow between adjacent blades in cylindrical or liner series of blades (cascade) can be quite different to that over isolated airfoils, the cascade lift and drag are different to those of isolated airfoil due to the interference that each blade has on the flow field around its neighbors[32-34]. 

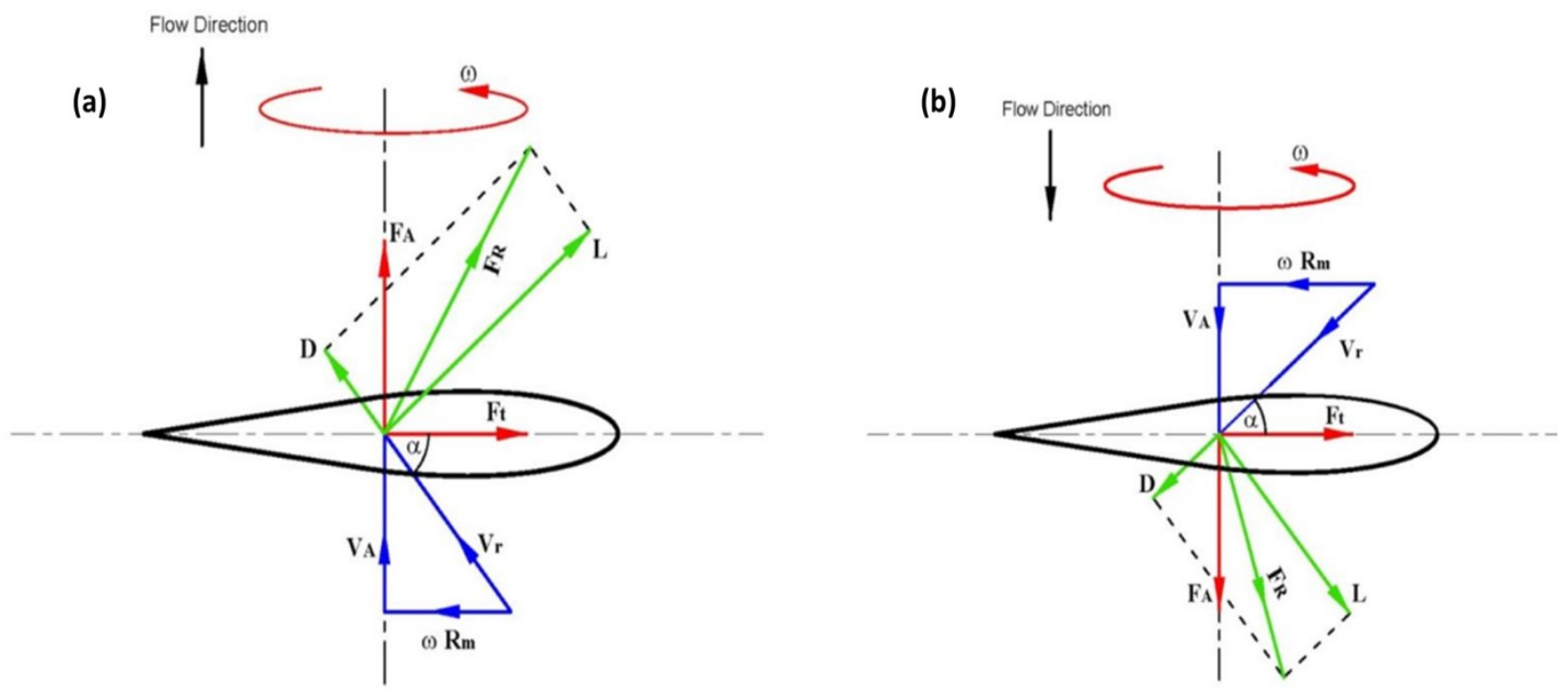

1

$$
F_{R}=\sqrt{L^{2}+D^{2}}
$$

(c)

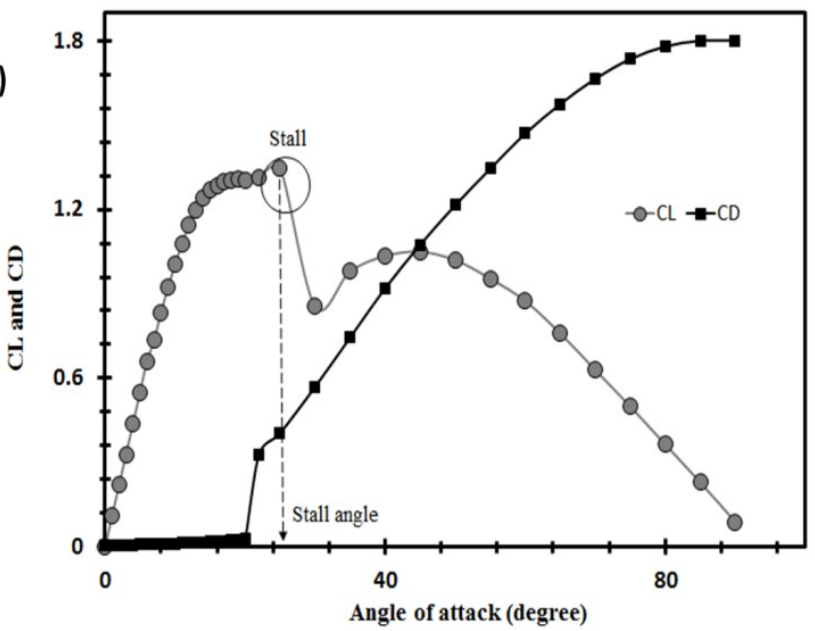

Figure 3 Aerodynamic forces (a) compression stages (b) suction stages (c) Lift and drag coefficient variation with angle of attack [29].

9 This force can be decomposed in two components into axial and tangential directions in terms of 10 lift and drag components as: 


$$
F_{A}=L \cos \alpha+D \sin \alpha
$$

1

and

$F_{t}=L \sin \alpha-D \cos \alpha$

where $F_{A}$ and $F_{t}$ are the axial and tangential forces, respectively.

Second, the Suction Stage, in which the water level drops, sucking air into the duct, and a similar velocity and force analysis can be described as shown in Figure 3 (b). A comparison between Figures 3(a) and 3(b) shows that the tangential force maintains the same direction during the two stages, while the axial force reverses its direction. For a symmetrical airfoil section, the direction of tangential force $F_{t}$ remains the same for both positive and negative values of $\alpha$. Such airfoil blades are set around an axis of rotation. The rotor rotates in the direction of $F_{t}$ or upward and downward strokes, regardless of the direction of airflow.

The vast majority of researchers assume that the force analysis resulting from the flow through the rotor can be reduced to a two-dimensional analysis. This assumption is based on the radial equilibrium theory $[35,36]$ where the force resulting from the radial velocity component is assumed to be negligible everywhere in the flow field except within the blade rows [16]. Nevertheless, there have been some studies citing the relevance of the radial force components. In such studies, it was assumed that the force resulting from the radial velocity component was far from being negligible [37-39]. Also, Falcao et al. reported that a fully three-dimensional force analysis should be performed, or at least corrections to two-dimensional flow results should be introduced. In addition, it could be assumed that the radial force component is negligible, if the rotor blade work per unit mass is constant along the span or, equivalently, if the velocity circulation about the blades does not vary along the radial coordinate. However, such conditions, although very common, are not generally satisfied in self-rectifying turbines for OWC applications [18].

From the electrical power engineering point of view, the W-T system can be seen as an $\mathrm{AC} / \mathrm{AC}$ converter, which converts a mechanical power signal with variable force and frequency into an electrical power signal with constant voltage and frequency [40]. W-T converts the bidirectional airflow into mechanical energy in the form of unidirectional shaft power, which is in turn used to move the wound rotor induction machine. The wound rotor machine controlled by rotor resistance has several advantages, such as high line power factor, absence of line current harmonics and smooth and wide range of speed control. As the external resistance is increased, 
the torque/slip curve becomes flatter, giving less speed, until the speed becomes zero at high

2 resistance [41].

The squirrel cage induction generator is normally preferred since it is cheap, small, rugged, maintenance-free, and does not require separate excitation and synchronization to the grid. It works as a motor when running below synchronous speed, and as a generator above synchronous speed. However, the use of double-fed induction generator has a huge potential in the development of distributed renewable energy sources. The double-fed induction generator is essentially an asynchronous machine, but instead of the rotor windings being shorted (as in a squirrel-cage induction machine), it is arranged to allow an AC current to be injected into the rotor, via the power converter. By varying the phase and frequency of the rotor excitation, it is possible to optimize the energy conversion. The frequency converter only has to process the generator's slip power fraction, which is generally no more than $30 \%$ of the generator rated power. This reduced rating for the frequency converter implies an important cost saving, compared to a fully rated converter $[41,42]$.

\subsection{Evaluation of techno-economic aspects}

The utilization of the sea wave was rarely considered on a practical scale prior to 1973 . However, a great deal of research has been conducted since 1973, the year of the so-called oil crisis [43]. In recent years, interest has revived, particularly in Japan, Britain and Scandinavia, so the research and small-scale development have progressed to the stage of commercial construction for power extraction. As with all renewable energy supplies, the scale of operation has to be determined, and present trends support moderate power generation levels at about 1 MW from modular devices about $50 \mathrm{~m}$ wide across the wave front. Such devices should be economic to replace diesel-generated electricity, especially on islands [7].

The predicted costs of wave power, in particular, have been falling against those of fossil fuels. The World Energy Council estimates that electricity from "arrays of mature devices located in promising wave energy sites" could cost from 5 cents to 10 cents per kilowatt-hour $(\mathrm{kWh})$. In fact, the Limpet, an on-shore oscillating water column device, began commercially generating electricity in Scotland in late 2000. At the time, the expected cost of Limpet's electricity was 7 cents to 8 cents per kWh [44]. And according to the Electric Power Research 
Institute (EPRI), the cost of ocean electricity production will drop significantly as the volume of production increases, as usually happens in the development and commercialization of any new technology. The electricity price produced from wave energy is still high but is forecasted to decrease with the development of the technology. This can be speeded up with initial financial and market support as it has been done in the past for preceding technologies such as wind, nuclear energy and oil.

Energy production costs are a major drive for the development of wave power - the lower they are, the faster the market grows. There are several levers to bring down costs of energy production systematically [45-48], including, in order:

1- Reliability of the equipment: The degree of reliability of a wave power concept largely drives project risk and thus the rate at which an investor expects a new investment to earn. Therefore, reliability is an important key for the customer.

2- Efficiency of the machine: Costs per kWh are, in simple terms, discounted cash-outflows for capital investments, operations and maintenance, divided by discounted number of $\mathrm{kWhs}$ produced. Hence, an increase of energy output works on the total investment - not only the turbine - and can bring costs down considerably.

3- Reduction of capital investment costs: The largest cost item on an OWC plant is the collector. Bringing this cost down has a significant influence on energy production costs. Apart from creative engineering, the best idea is to avoid spending large sums on the collector by sharing it with other applications. This is how the idea of the active breakwater application was born.

For coastal protection, large concrete structures are built in order to protect harbours from waves. If these structures are modified so that OWCs can be included in the front wall, costs can be shared and, according to laboratory measurements, loads on the walls can be significantly reduced. For a caisson type breakwater, an empty concrete structure with a rectangular structure of concrete enforcement walls is cast. In this state, the structures are floating and can be towed into position by a ship. The empty chambers are then filled with stones or sand so that the structure can sink and sit rigidly on the seabed. If the front chambers of the wall are only partly filled and openings under water are included, an OWC chamber can be formed [49, 50]. The W$\mathrm{T}$ is placed into the airflow. In this configuration, the breakwater is converted into an active 
1 breakwater, which not only protects the coast but also produces energy. Harbours usually require

2 a high level of electrical energy and therefore offer good opportunities for grid connection. In

3 effect, a fully integrated engineering development approach would appropriately design a

4 shoreline OWC in order to find the best compromise between cost and performance. Following

5 this path would lead to differences between a W-T configuration, notably in terms of the OWC

6 design and choice of location [51]. However, compared to W-T, other types of wave energy

7 converters are more expensive and have more complex designs.

8

\section{Existing W-T stations}

Since the 1970s, there have been a number of wave energy projects based on W-T. Table

112 provides a summary of all reported W-T projects. The LIMPET [52-57] and Pico projects [58-

12 63] are shoreline mounted systems. The OSPREY [64] is an example of near shore W-T projects

13 with the Trivandrum $[47,48]$ and Sakata projects $[45,46]$ are examples of breakwater devices. In

14 addition, the Mighty Whale is an offshore floating type [65]. These projects are necessary to the

15 current understanding and improvement of W-T technology and in many cases serve as test beds

16 and data collection tools.

17

Table 2 Summary of the existing W-T projects

\begin{tabular}{|c|c|c|c|c|c|c|}
\hline Devices & Location & building & Output & $\begin{array}{c}\text { No. of } \\
\text { turbines }\end{array}$ & Diameter & Type of turbine \\
\hline Sanze shoreline gully & Gully,Japan & 1984 & $40 \mathrm{~kW}$ & 2 & - -NA- & -NA- \\
\hline Kvaerner-Brug, Norwegian OWC & Toftestallen, Norway & 1985 & $500 \mathrm{~kW}$ & 1 & -NA- & -NA- \\
\hline Sakata, Japan & Sakata, Japan & 1989 & $60 \mathrm{~kW}$ & 1 & $1.337 \mathrm{~m}$ & $\begin{array}{c}\text { Monoplane with } \\
\text { guide vanes }\end{array}$ \\
\hline Prototype OWC device[66] & Islay,Scotland & 1991 & $75 \mathrm{~kW}$ & 2 & $1.2 \mathrm{~m}$ & Biplane \\
\hline Vizhinjam OWC & Trivandrum, India & 1991 & $150 \mathrm{~kW}$ & 1 & $2 \mathrm{~m}$ & Monoplane \\
\hline OSPREY & Dounreay, Scotland & 1995 & $2 \mathrm{MW}$ & 4 & $3 \mathrm{~m}$ & Contra-rotating \\
\hline Mighty Whale & Japan & 1998 & $120 \mathrm{~kW}$ & 1 & $1.7 \mathrm{~m}$ & $\begin{array}{c}\text { Monoplane with } \\
\text { guide vanes }\end{array}$ \\
\hline The Pico Power Plant & Azores, Portugal & 1999 & $400 \mathrm{~kW}$ & 1 & $2.3 \mathrm{~m}$ & $\begin{array}{c}\text { Monoplane with } \\
\text { guide vanes }\end{array}$ \\
\hline LIMPET & Islay,Scotland & 2000 & 500 & 2 & $2.6 \mathrm{~m}$ & Contra-rotating \\
\hline
\end{tabular}




\begin{tabular}{|c|c|c|c|c|c|c|}
\hline & & & $\mathrm{kW}$ & & & \\
\hline Shanwei, Guangdong, China & Shanwei, Guangdong, China & 2001 & $100 \mathrm{~kW}$ & -NA- & -NA- & -NA- \\
\hline Mutriku Wave Energy Plant[49, 50] & Basque Country, Spain & 2009 & $296 \mathrm{~kW}$ & 16 & $1.25 \mathrm{~m}$ & Biplane \\
\hline
\end{tabular}

Several studies have investigated the overall performance of $\mathrm{W}-\mathrm{T}$ in existing shoreline installations with the aim of improving its efficiency. For example, the W-T prototype installed in Islay, Scotland is investigated in $[67,68]$. The Vizhinjam OWC was installed in Trivandrum, India in 1991 and is investigated in [69]. Numerical simulation of [69] shows an increase of turbine output power for a numerical module with control mechanism (by varying the rotor resistance of the induction machine) as compared to an uncontrolled one, for the same variation of differential pressure (aerodynamic input, $\mathrm{N} / \mathrm{m}^{2}$ ). The performance of the contra-rotating W-T installed in the LIMPET is compared to the predicted performance from theoretical analysis and model tests in [70]. It is found that a contra-rotating W-T has a lower efficiency than a biplane or monoplane W-T with guide vanes. In addition, a contra-rotating W-T requires an additional generator, or a gearbox.

\section{Performance parameters of $\mathbf{W}-\mathbf{T}$}

There are several factors that influence the design, hence performance, of W-T $[6,16$, 71]. The optimization and improvement of such parameters aim mainly at overcoming the existing disadvantages of the system. Typical W-T systems show several well-known drawbacks: low tangential force, leading to low power output from the turbine; high undesired axial force; a relatively low aerodynamic efficiency; and a limited range of operation due to stall. This section of the article aims at reviewing the efforts done to overcome such disadvantages and improve the performance by controlling the design parameters.

\subsection{Guide vane}

In a number of previous studies, it was concluded that the delay of stall onset contributes to improving W-T performance. This delay can be achieved by setting guide vanes on the rotor's hub as illustrated in Figure 4. 


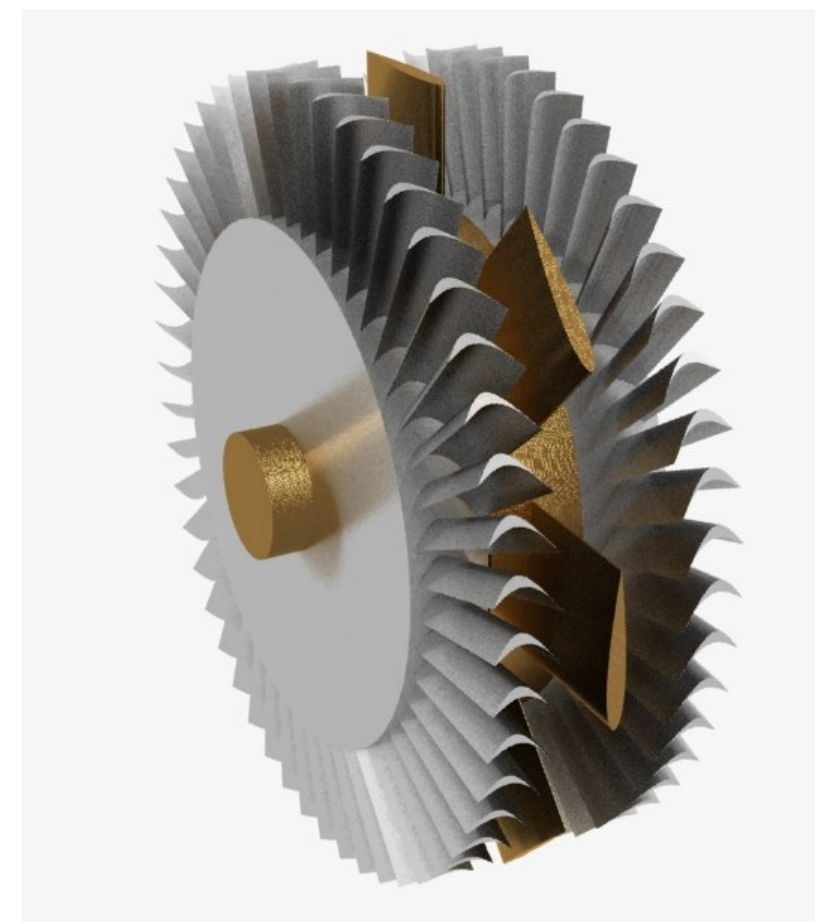

Figure 4 Illustration of guide vanes installed with $\mathrm{W}$-T rotor

The variables that affect the aerodynamic performance of a $\mathrm{W}-\mathrm{T}$ are discussed in $[16,71]$, and it was found that the swirl losses at the turbine exit can be reduced by the use of guide vanes. Also, a multi-plane turbine without guide vanes was less efficient (approximately 20\%) than the one with guide vanes. By testing a W-T model under steady flow conditions, and using the computer simulation (quasi-steady analysis), a comparison between W-Ts having 2D guide vanes and 3D guide vanes is conducted $[72,73]$. It showed that the $3 \mathrm{D}$ case has superior characteristics in the running and starting conditions. The results of mathematical simulations considering several aerodynamic designs of the W-T are shown in Table 3 [74]. Different guide vanes designs were compared and investigated analytically [75], taking into account the turbine starting characteristics and efficiency in irregular wave conditions. Table 4 shows the best two designs, but for the total performance, R7N08N65 G15N11S40 is recommended. R7N08N65 has rectangular blades, a solidity of 0.7 , normal blades, 8 blades, and a TC (the gap between the casing and blade tip) of $0.65 \mathrm{~mm}$. The G15N11S40 has 1.5 solidity, 11 blades, and the axial spacing between rotor and guide vane $=40 \mathrm{~mm}$.

Table 3 A summary of the performance data for the different turbines, [74]

\begin{tabular}{|c|c|c|c|c|}
\cline { 2 - 5 } \multicolumn{1}{c|}{} & \multicolumn{2}{c|}{ NACA0015 } & \multicolumn{2}{c|}{ HSIM 15-262123-1576 [76] } \\
\hline \multirow{2}{*}{ Max. Efficiency } & Without guide vanes & with guide vanes & Without guide vanes & with guide vanes \\
\cline { 2 - 5 } & $58 \%$ & $71 \%$ & $55 \%$ & $67 \%$ \\
\hline
\end{tabular}


Table 4 Maximum efficiency with minimum torque and starting torque coefficients [75]

\begin{tabular}{|c|c|c|c|}
\hline Turbine Profile & Maximum efficiency & $\begin{array}{c}\text { minimum torque } \\
\text { coefficient }\end{array}$ & $\begin{array}{c}\text { starting torque } \\
\text { coefficient }\end{array}$ \\
\hline R7N08N65 G15N11S40 & $44.8 \%$ & 0.41 & 0.49 \\
\hline R7N08F65 G15N21S31 & $47.4 \%$ & 0.08 & 0.33 \\
\hline
\end{tabular}

3

\subsection{Hysteretic behavior}

As shown in Figure 5, due to the reciprocating flow, the performance of the W-T has a hysteretic loop in which the values of $C_{A}$ and $C_{T}$ in the accelerating flow are smaller than those in the decelerating flow. Hysteresis characteristics are produced by the pressure difference induced by the different behavior of wakes between an accelerating flow and a decelerating flow in the same angle of attack, as illustrated in Figure 5.

A considerable number of parametric studies, using experimental and numerical approaches, are presented in [16]. It is found that the hysteresis effects are caused by asymmetry in the boundary-layer development on the blade surface and oscillating motion of the wake, the extent of which can be appreciable at low Reynolds numbers. Hysteresis effects are found to be directly proportional to the turbine solidity [16] and blade thickness [77] and insensitive to blade AR and surface roughness [77]. These effects can be smaller on large-scale turbines where the boundary layer on the blades is turbulent and relatively thin. A CFD model of W-T is used to investigate the hysteretic behavior in [78]. The blade angle of attack is also found to be directly proportional to the hysteretic effects. In order to investigate the mechanism of the hysteretic behavior of W$\mathrm{T}$ and also the effect of solidity, setting angles and blade thickness on the hysteretic behavior of $\mathrm{W}-\mathrm{T}$ (where the setting angle is defined as an angle between the blade chord line and the rotational direction of rotor, $\omega R_{m}$ ), CFD simulations are conducted for the flow field around a blade of a W-T by $[79,80]$. It is found that the mechanism to change the vortex intensity in the wake can be explained according to the vortex theorem. The vortex is intensified by the clockwise trailing shed vortices in the accelerating flow process, while it is suppressed by the counterclockwise vortices in the decelerating flow 
process. The hysteretic characteristics in sinusoidal flow are experimentally assessed in four kinds of turbines (NACA0020; NACA0015; CA9; and HSIM 15-262123-1576) in $[81,82]$. It is found that all turbines have similar hysteretic loops; however, the hysteresis characteristics of the W-T are less sensitive to the blade profile than to solidity, setting angles and blade thickness.
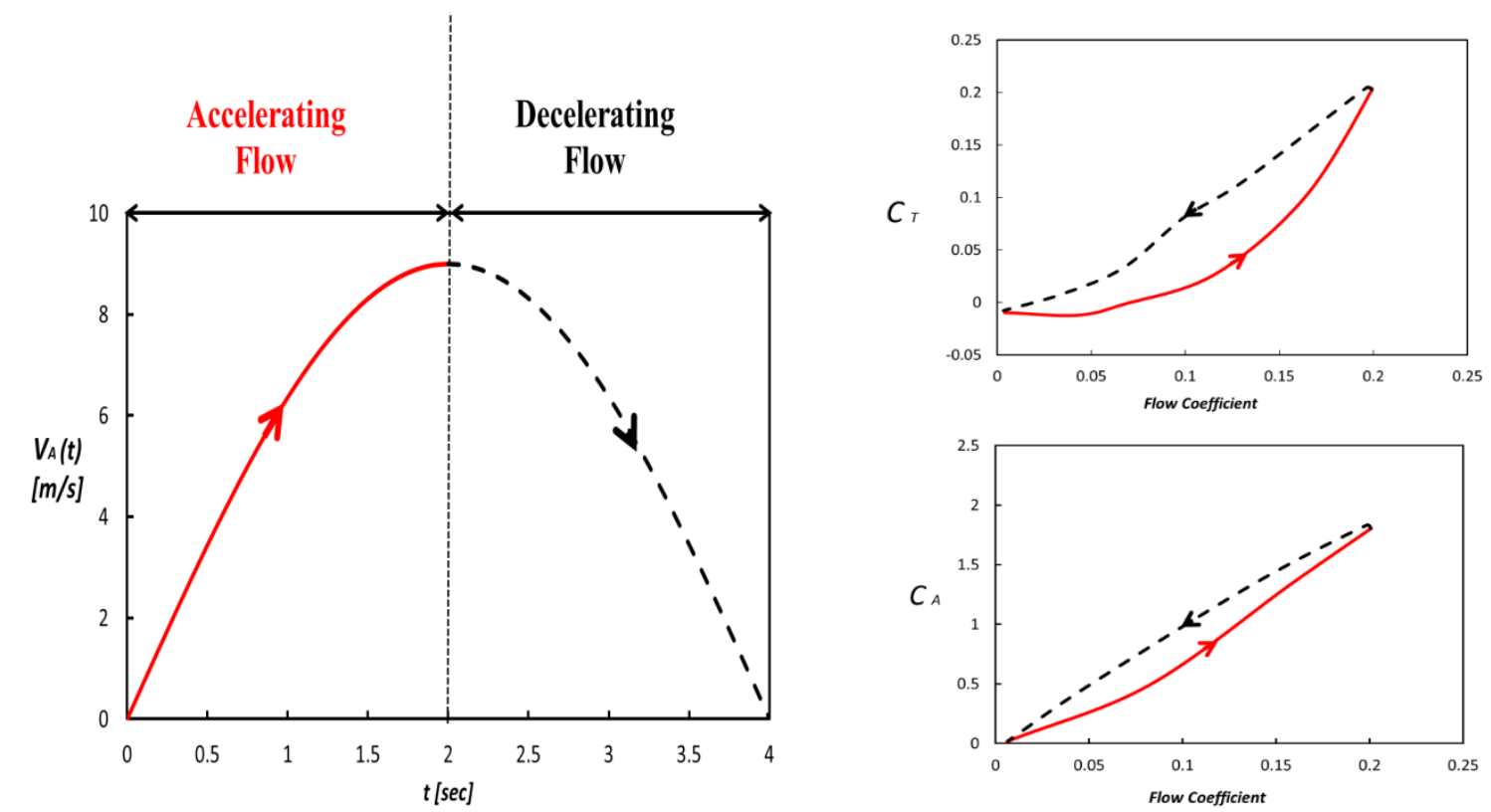

Figure 5 Typical Hysteresis loop obtained in the W-T for one-half cycle of the sinusoidal flow in the unstalled condition. Graph reproduced after [4]

Numerical simulations are conducted for the hysteretic behavior of monoplane and biplane W-Ts in [83-85]. It is found that for the monoplane W-T, the hysteretic loop is opposite to the well-known dynamic stall [86-91] of an airfoil. The hysteretic behavior is associated with a stream wise vertical flow appearing near the suction surface. For the biplane $\mathrm{W}-\mathrm{T}$, the hysteretic behavior is similar to that of the monoplane at lower attack angles. However, the hysteretic loop similar to the dynamic stall is observed at higher attack angles, which is attributed to unsteady flow separation near the hub and the trailing edge of the suction surface of the upstream blade. The magnitude of hysteretic loop is further decreased in the biplane turbine with staggered blades than the one without stagger. 
The effects of blade profile and rotor solidity on hysteretic behavior of W-T operating under bi-directional airflow have been experimentally studied in $[92,93]$. It is shown that the size of hysteretic loop of pressure coefficient greatly decreases with the reduction in rotor solidity. Such characteristics are less sensitive to blade profile, as shown in $[81,82]$. However, the effects of the TC region cause a reduction of the maximum torque coefficient and a decrease of the hysteretic behavior[94]. The effects of unsteady flow conditions on the performance of a monoplane W-T without guide vanes during a field experiment on a OWC device are described in $[95,96]$. The torque coefficient shows a hysteretic mechanism characterized by a counter-clock-wise loop that appears with high frequency oscillations. A dynamic stall phenomenon appears with oscillations of very large amplitude, independently from the frequency.

\subsection{Multi plane W-T}

For W-T systems that operate at high pressure values, a multi plane (usually tow stage) turbine configuration can be used. Such a concept avoids the use of guide vanes, and therefore the turbine would require less maintenance and repairs[16]. The biplane WT, see Figure 6 (a) and the contra-rotating W-T see, Figure 6 (b) are investigated to achieve this purpose. 
(a)

(b)
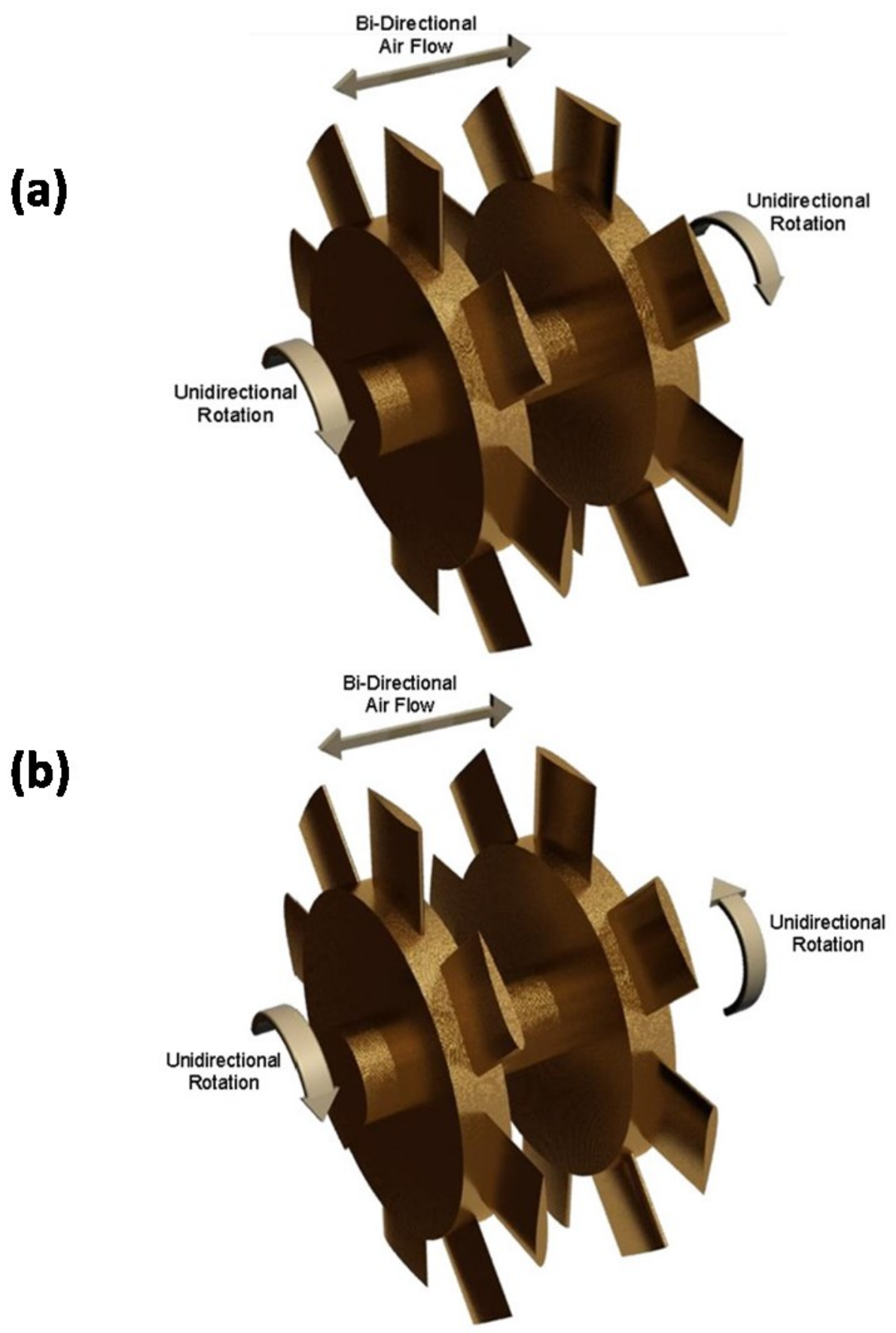

Figure 6 Multi plane W-T (a) bi-planes W-T (b) contra-rotating W-T

The performance of a biplane $\mathrm{W}-\mathrm{T}$ is dependent on the gap between the planes, as shown in [16]. A gap-to-chord ratio between the planes of 1.0 is recommended for the design of biplane $\mathrm{W}-\mathrm{T}$ in order to achieve high efficiency in a limited space. A multiplane turbine without guide vanes is less efficient than that with guide vanes but is 
relatively simple to design. A high solidity mono plane or a biplane W-T is a simple configuration but has large kinetic energy losses due to swirl at the exit. Experimental results in [97] show that the use of two twin rotors rotating in the opposite direction to each other is an efficient means of recovering the swirl kinetic energy without the use of guide vanes.

The overall performance of several types of W-T design has been studied in [98] and by using a semi-empirical method for predicting the performance in [99]. Similar comparisons are undertaken using experimental measurement in [100]. Monoplane, biplane, monoplane with guide vane and contra-rotating turbines viscous losses on the turbine rotors constitute the largest part of the losses. Therefore, the recovery methods have specific operational ranges. The contra-rotating turbine has an operational range that is similar to that of the monoplane turbine with guide vanes and achieves similar peak efficiency. However, the flow performs better than later in the post-stall region. The value of peak efficiency of contra-rotating turbine is higher than that of monoplane turbine without guide vane by $12 \%$ and by $9 \%$ for biplane turbine. It is also evident in [100] that the swirl component determines which rotor of a multi-plane turbine will stall first. On quite the contrary, investigated in [70] are use theoretical analysis and model tests to the predicted performance of the contra-rotating W-T installed in the LIMPET, and it is found that a contra-rotating W-T has a lower efficiency than that of a biplane or monoplane W-T with guide vanes. In addition, a contra-rotating W-T requires an additional generator, or a gearbox, to reverse the direction of rotation of one rotor.

Two-stage W-Ts with symmetric and non-symmetric airfoils have been investigated in [101]. Numerical optimization procedure has been carried out to optimize the performance of the turbine as a function of the non-dimensional gap between the two rotors. It leads to an optimal value of the non-dimensional gap near 0.85 when simultaneously considering the request of maximum tangential force coefficient, of maximum efficiency for the prescribed operating range (angle of incidence $=8$ to 14 degree) and the needed size of the system.

Detailed numerical analysis of biplane W-T performance has been performed in [102]. The downstream rotor curbs the turbine during start up and therefore delays its start up. Also, it produces $10-30 \%$ of the total turbine torque and $40 \%$ of the total 
pressure drop during normal operation. The downstream rotor has an efficiency of 20$60 \%$ of the upstream rotor efficiency during normal operation. Exergy analysis is also performed using the numerical simulation for steady state biplane W-Ts. The upstream rotor has a design second law efficiency of $82.3 \%$, although compared to the downstream rotor second law efficiency of $60.7 \%$.

\subsection{Flow through W-T}

It is important to design a turbine that has as high operating aerodynamic efficiency as possible and is matched with the OWC system for pressure drop and flow rate over a wide range of sea conditions. For this purpose, many studies have investigated the flow through the turbine, see (Figure 7).

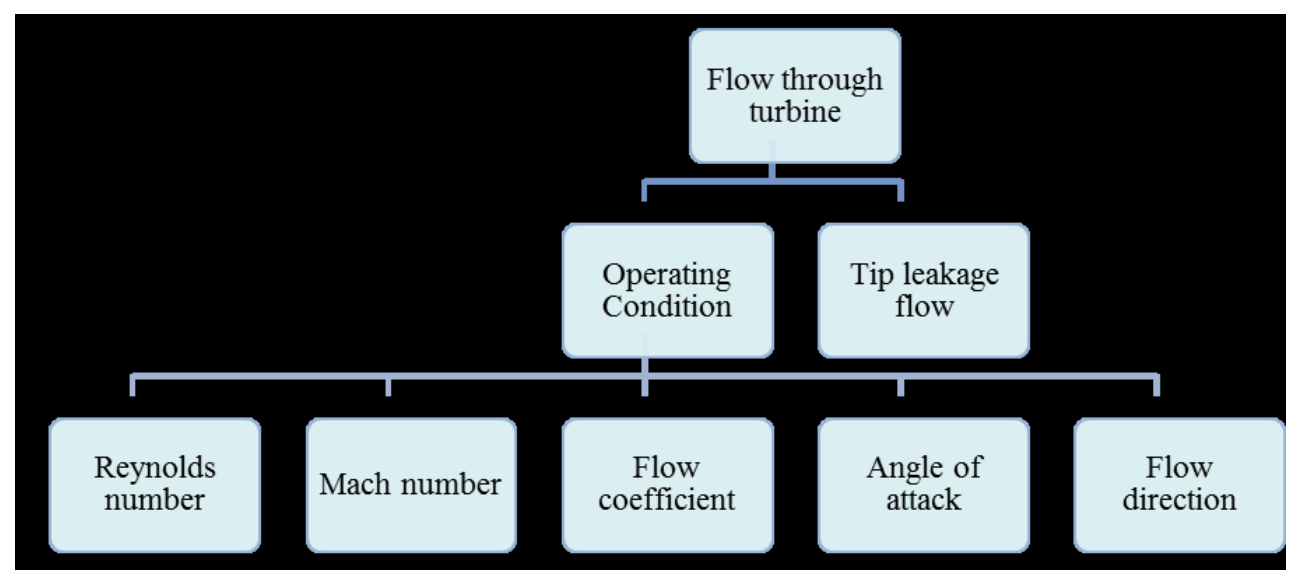

Figure 7 flow over turbine parts and operating condition parameter

The basic principles and procedures for designing a W-T for a wave energy power station are described in [71]. The aerodynamic efficiency increases with flow ratio up to a certain critical value, after which it decreases. In order to avoid transonic effects, the maximum Mach number on the blades should be less than the critical Mach number. However, the critical Mach number decreases with an increase in incidence or solidity. Finally, the turbine maximum efficiency increases with an increase in Reynolds number.

The prediction methods and the variables that affect the aerodynamic performance of a W-T are reviewed in [16]. It shows that W-T is less sensitive to inlet turbulence compared to conventional turbo-machines. The performance of a turbine in sinusoidal flow is better than that in a random air flow. 
The use of CFD method to investigate the performance of a W-T is described in [103]. It is found that stalling of the flow does not occur first at the blade root and spread outward. It appears rather to be associated with the TC vortex and to spread inboard from the near-tip region.

A computational model has been used in [104] to study the performance and aerodynamics of the turbine, quantitatively and qualitatively. In addition, it is used to study the flow coefficient, turbine stalls and the appropriate inlet velocity profile. It is found from the computed results that the wakes behind the turbine blades (NACA0021) merge rigorously in the portion of Radius ratio $=0.45: 1.0$, which leads the turbine to stall. The TC leakage flow is considerably higher in the trailing edge portion. However, as the flow coefficient increases, leakage flow region advances towards the leading edge, causing a large mass flow of air to leak through the gap.

The flow-field through a high solidity $(\sigma=0.6366) \mathrm{W}-\mathrm{T}$ using blades with constant chord NACA0015 profiles is described in details in [38]. Separation at the outer radii has been detected for high values of the flow rate, which turns out to be induced by a radical shift of the mass flow through the turbine, mainly due to the cascade effect [30].

Numerical simulations have been performed to examine the flow-field through the turbine blades at different flow-rates in [37]. It is found that the flow separation at the tip is detectable by the presence of the pressure plateau along the suction side at coefficient $=0.238$ and, more importantly, at coefficient $=0.257$.

An analysis, based on the actuator disk theory [105-107], is presented, and results are compared with corresponding CFD simulations in [39]. It is illustrated that for low values of flow coefficient, flow separation occurs near the rotor hub rather than at the blade tip, consequently improving the global turbine performance.

Numerical simulations are performed in [108] to indicate that pressure and torque coefficients increase when the flow rate coefficient increases. Highest calculated efficiency of the W-T in [108] is calculated to be around $60 \%$ for non-dimensional flow coefficient $=0.155$. Operation of one OWC plant would produce $1850 \mathrm{kWh}$ of energy per year for the assumed average sea regime data in the Adriatic Sea[109].

Experimental characterization of W-T with NACA0015 profiles submitted to a bidirectional flow is carried out, and the results are presented and analyzed in [110]. For 
several test conditions, the maximum efficiency (approximately from 0.3 to 0.43 for different test) of the turbine is always obtained for values of the flow coefficient between 0.19 and 0.21 .

The entropy generation, due to viscous dissipation, around W-T has been recently examined by the authors in $[27,111]$. NACA0015 gives a less global entropy generation rate and a higher efficiency rate compared with other airfoils. From the study of the behavior of four different airfoils, NACA0015 is not the best airfoil in all conditions. For example, at maximum Reynolds number, NACA0012 gives a less global entropy generation rate, and NACA0020 creates the minimum value, so it is a good concept to create an optimum design airfoil that gives better results than NACA0015. This study suggests possible existence of critical Reynolds number at which a viscous irreversibility takes minimum values.

\subsection{Design optimization}

This subsection reviews different methods to optimize the design of W-T in order to improve its overall performance: by changing in blade dimension or position, by adding plate on the blade or finally by creating a new blade shape, see (Figure 8). 


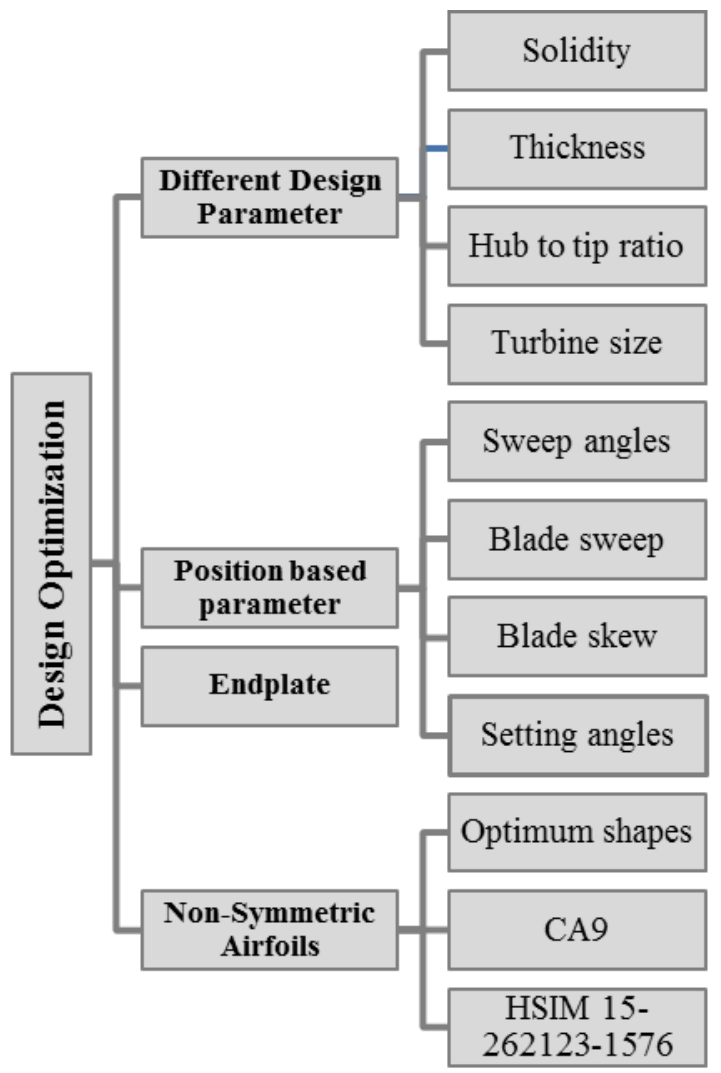

Figure 8 design optimization parameter and sub parameter

\subsubsection{Different design parameter for turbine}

Various wind tunnel tests on NACA four-digit airfoils in a tandem cascade with the angles of incidence ranging from 0 to 90 degree are described in [30]. The increase in the blade thickness results in larger negative values of torque coefficient and has a favorable effect on starting.

The prediction methods and the variables that affect the aerodynamic performance of a W-T are discussed in $[16,71]$. A large solidity is needed for the turbine to be selfstarting. It is advisable to choose a thicker profile for small-scale turbines and a thinner profile for a large-scale turbine. Values of hub-to-tip ratio approximately equal to 0.6 are recommended for design.

The ability of a 3-D CFD method to predict the effect of solidity on the performance of a monoplane W-T has been tested by [112]. Calculations of the effect of solidity on turbine performance are predicted both qualitatively and quantitatively, and the effect of clearance is qualitatively correct. 
The operational matching of the performance of the turbine is used as the premise in achieving an optimal design configuration and sizing. The range and frequency of power bands presented to the turbine over long periods of time are in [113], which results in a 5\% improvement in power output with the optimal size of the turbine required to be slightly larger than the average pneumatic power rating would suggest.

\subsubsection{Position based parameter}

The change in the position of blade according to the hub centerline through different parameters (sweep angle, blade sweep, blade skew and setting angles) has a direct effect on the performance of turbine.

\subsubsection{Sweep angle, blade sweep and blade skew}

An experimental work is presented to investigate and compare the aerodynamic performance of the backward swept, see Figure 9 (a), and unswept angle blades for different rotor solidities (0.64 and 0.32) for 0 degree and 20 degree setting pitch angles in [114]. Results for the 0 degree setting pitch angles have shown that the swept back angle blade produces a more positive value of efficiency and torque than that of the standard unswept blades but at the expense of peak efficiency. The experimental results show that this sweeping back angle has to be minimized in order to reduce its detrimental effect on the overall turbine efficiency.

The calculations of the blade sweeps for the W-T, see Figure 9 (b), with a numerical code by [115] and experimentally with quasi-steady analysis in [82]. As a result, it is found that the performance of the W-Ts is influenced by the blade sweep, and a suitable choice for the sweep ratio is $35 \%$. 
(a)

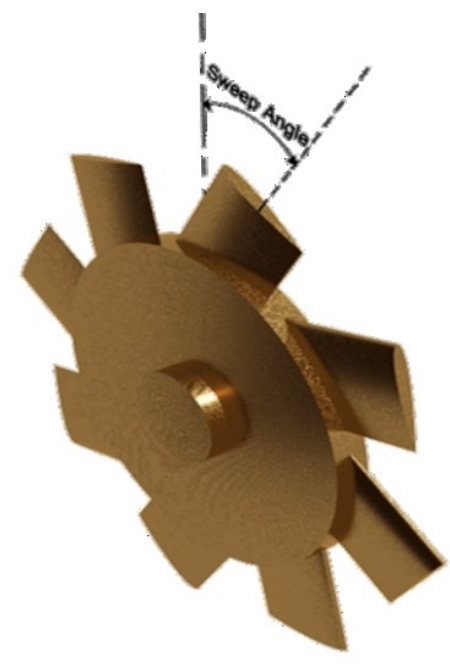

(c)

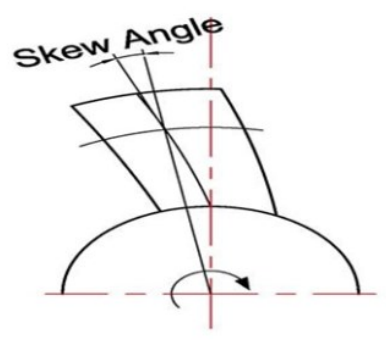

(b)
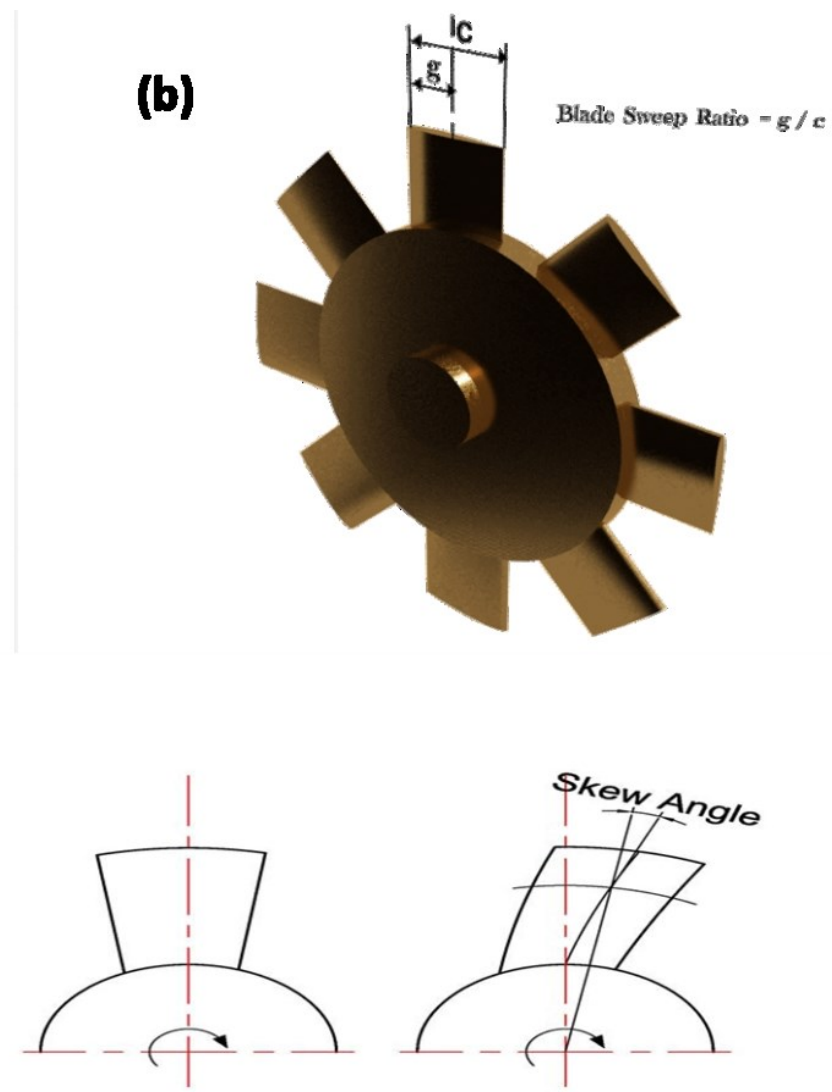

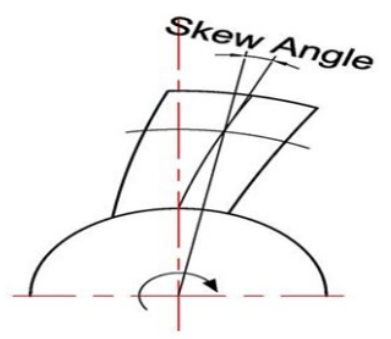

1

Figure 9 Position based parameter (a) backward Sweep angle (b) Blade Sweep Ratio (c) Blade Skew: left: backward skewed blade; middle: straight blade; right: forward skewed blade [116]

The effect of blade skew, see Figure 9 (c), on the aerodynamic performance and associated aerodynamic noise is assessed in [116] by using both numerical simulations and experiments to develop an analytical blade design tool for W-Ts, incorporating blade skew. Inception of stall inevitably causes an increase of specific sound power level by up to $20 \mathrm{db}$. The backward/forward blade skew delays the onset of stall and extends the turbine's range of stall-free operation by $106 \%$ of the baseline. The flow generated sound in unstalled operation was decreased up to $3 \mathrm{db}$ by optimal backward / forward blade skew. 


\subsubsection{Setting pitch angles for blade.}

Setting the blades at their optimum pitch angle during compression and suction is expected to substantially improve W-T efficiency [117-124]. This is achieved by the turbine manufacturer in such a way to allow the turbine blades to rotate around their axis with an angle that equals \pm optimum blade setting pitch angle.

The performance of W-T using self-pitch-controlled blades taking real air flows to the turbine into account is clarified by [125]. Experimental investigations and computer simulations using a quasi-steady analysis are performed on the optimum setting angle during suction, and it is found to be 6 degrees while the one during compression is found to be 10 degrees.

A modified W-T with setting angle has been investigated by model testing and numerical simulation in [126]. It is found that the new turbine using rotor blades with a fixed setting angle is superior to the conventional W-T, and that the optimum setting angle was 2 degree for compression velocity amplitude to suction velocity ratios 0.8 and 0.6 , in both with guide vanes and without guide vanes configurations.

A $400 \mathrm{kw}$ variable-pitch $\mathrm{W}-\mathrm{T}$ is built to be tested in the Pico plant, Azores, Portugal alongside a fixed pitch W-T of a similar rating [127]. It is hoped that the variable-pitch W-T will demonstrate increased net energy productivity. Therefore, the variable-pitch turbine should be able to demonstrate increased energy productivity compared to that of fixed-pitch machines. Moreover, the eddy-current pitch actuation system should provide responsive and energy efficient pitching, but it was never installed. The relatively modest efficiency of the W-T, especially when operating in the compressor mode, severely limits the gains from reactive control.

A numerical optimization algorithm based on CFD simulation is implemented in order to optimize the blade pitch angle in [128]. The standard NACA 0021 and AOP are numerically investigated. The present CFD optimization results show that the optimum blade pitch angle for NACA 0021 is +0.3 degree while that of the AOP equals +0.6 degree. The present airfoils with the optimized pitch angle show an average efficiency improvement of $3.4 \%$ for standard NACA 0021 and $4.3 \%$ for the AOP.

A numerical optimization algorithm is implemented in this work [129]. The present CFD optimization results show that the optimum blade pitch angle for NACA 0021 is 0.3 
degree while that of the optimized blade equals 0.6 degree. Up to $2.3 \%$ improvement in NACA 0021 turbine efficiency and 6.2\% improvement in AOP efficiency are achieved.

\subsubsection{Endplate}

In order to improve the performance of the $\mathrm{W}-\mathrm{T}$, the effect of end plate, see Figure 10, on the turbine characteristics has been examined in [130, 131]. Using an experimental model and CFD method shows that the optimum plate position was a forward type. Also, the peak efficiency increases approximately $4 \%$ as compared to the $\mathrm{W}-\mathrm{T}$ without an endplate.
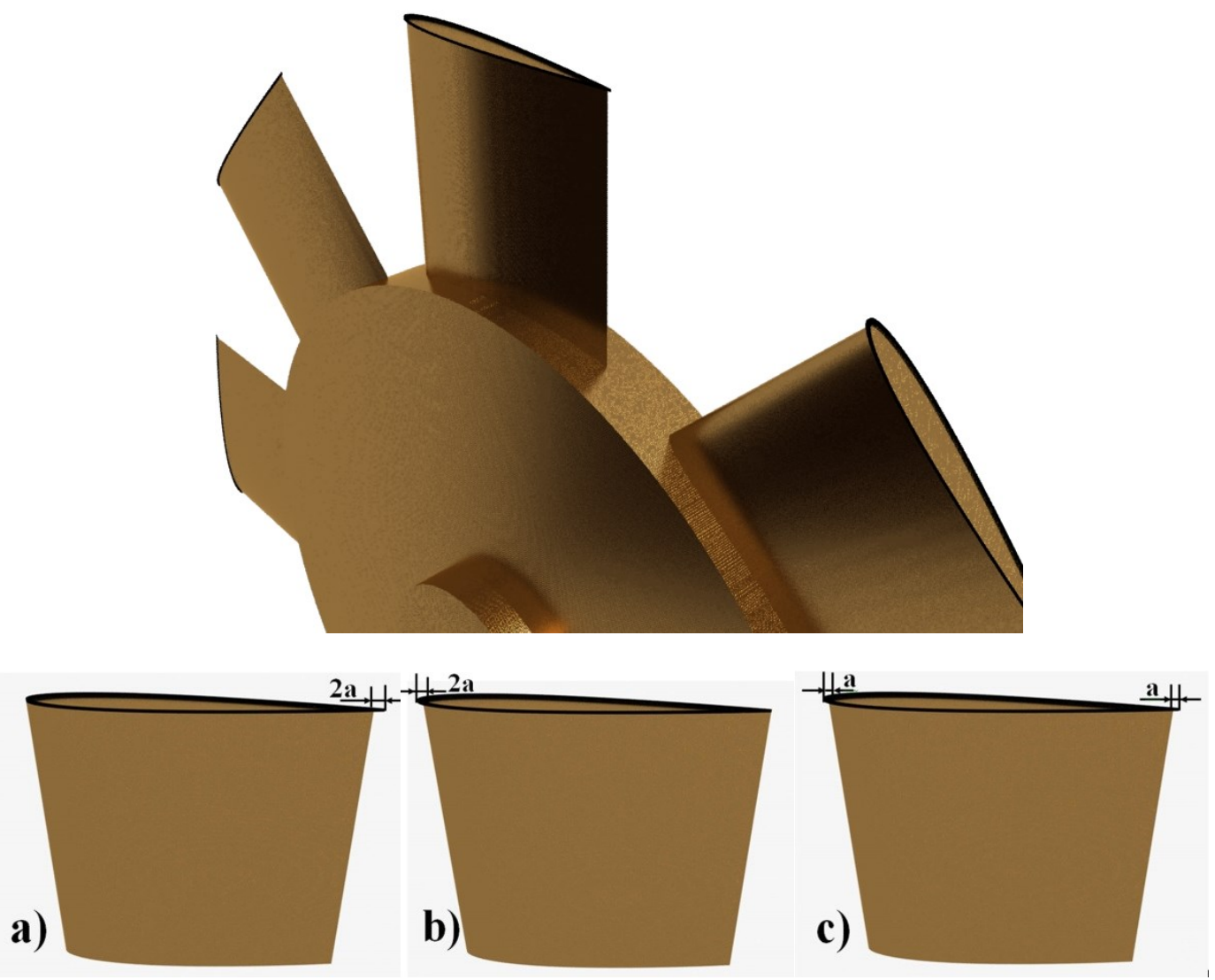

Figure 10 Rotor blade with end plate a) backward type; ; b) forward type c) middle type

\subsubsection{Non-Symmetric airfoils}

A methodology for numerical simulation of a CA9 rotor W-T is presented in [132]. Researchers have stressed the use of traditional symmetrical NACA series blades until they developed an optimized profiles: CA9, which has the same thickness as NACA0015 and is optimized in terms of the leading edge radius, maximum thickness position and trailing edge slope [133, 134]. It shows 
superiority over a standard NACA0015. A maximum efficiency of $70 \%$ is obtained, and the overall computed performance related to reasonable qualitative agreement with experimental one.

The calculations of the blade sweeps for the W-T with the NACA0020 and the CA9 blades are carried out to clarify the performance with a numerical code by [115]. The overall performances for the NACA0020 blade are better than those for the CA9 blade. Generally, the blade thickness is thinner on NACA four digit series, while the maximum efficiency is higher and the stall margin deteriorates. However, both the maximum efficiency and the stall margin for the NACA0020 blade in this calculation are better related to those for the CA9 blade.

Four kinds of blade profile are selected with regard to the blade profile of the $\mathrm{W}$ $\mathrm{T}$ in $[81,82,135]$. The types of blade profiles are as follows: NACA0020, NACA0015, CA9, and HSIM 15-262123-1576. The experimental investigations have been performed for two solidities $(0.48$ and 0.64$)$ by experimental testing (steady flow conditions) and numerical simulation using a quasi-steady analysis (running and starting characteristics under sinusoidal flow). As a conclusion, NACA0020 is superior to other turbines (NACA0020; NACA0015; CA9; and HSIM 15-262123-1576) in the small-scale model testing. For a large-scale W-T operated at high Reynolds number, a suitable choice is the blade profile of NACA0015. However, the experimental investigations operating under sinusoidal and real sea conditions in $[92,93]$ conclude that the preferred rotor geometry is CA9 blade profile, with rotor solidity 0.64 .

Two-stage W-Ts with symmetric and non-symmetric airfoils have been investigated in [101], and the numerical algorithms are used to estimate the optimum shape with an increase of efficiency (by 2.1\%) and of tangential force coefficient (by 6\%), compared to the standard NACA 2421. An optimization process is employed in order to increase the tangential force induced by a monoplane W-T in [136]. A relative increase of the tangential force coefficient exceeding $8.8 \%$ (as a mean, $11.3 \%$ ) is obtained for the full operating range. At the 
same time, the efficiency improves also by at least $0.2 \%$ and up to $3.2 \%$ (as a mean, $1 \%$ ) compared to the standard NACA 0021.

A comparison of total entropy generation, due to viscous dissipation, between a suggested design (variable chord) and a constant chord W-T is presented in [137]. The detailed results demonstrate an increase in static pressure difference around new blade and a $26.02 \%$ average decrease in total entropy generation throughout the full operating range.

\subsection{Tip clearance}

The gap between the casing and blade tip is a very effective parameter on the turbine behavior. The effect of the flow around the tip is more significant in the process of turbine stall than that around the hub [138-140].

The prediction methods and the variables that affect the aerodynamic performance of a $\mathrm{W}-\mathrm{T}$ are discussed in $[16,71]$. The $\mathrm{W}-\mathrm{T}$ is very sensitive to TC when compared to conventional turbines. Therefore, values of a TC ratio less than 0.02 are recommended for design.

The ability of a 3-D CFD method to predict the effect of TC on the performance of a monoplane $\mathrm{W}-\mathrm{T}$ has been tested in [112]. It is shown that as the TC increases, the performance of the turbine drops.

In order to examine the effect of the extent of the TC on the steady performance of the turbine, the results of numerical computations performed with different TC $(1 \%, 5 \%$ and $10 \%$ of the chord length) and different flow conditions $(0.15,0.225$, and 0.275$)$ are illustrated in [38]. The stagnation pressure drop coefficient decreases when increasing the TC. On the other hand, the torque coefficient decreases when increasing the TC. In fact, the gap must be neither too small in order to avoid flow separation already existing at low values of the flow coefficient nor too large in order to avoid too small performance caused by small pressure drop through the turbine and large tip leakage flow.

A comparison between numerical and experimental investigations is conducted in [141] for studying uniform TC ratio. Regarding turbine efficiency, it is found that the peak efficiency of the turbine decreases and shifts towards a higher flow coefficient as the TC to chord length ratio increases, while the stall margin becomes wider. 
The performance of a W-T with various non-uniform TC is examined using CFD by [142]. The performance of turbines with uniform and non-uniform TC is compared. It is shown that the turbine with non-uniform $\mathrm{TC}$ seems to have a preferable overall performance.

CFD models based on the LIMPET OWC turbo generation section are studied in [143] to investigate how airflow impingement created by a rotating turbine directly upstream increases the heat transfer away from an electrical generator, and also how this could be increased by adjusting the clearance between the turbine tips and shroud. As the clearance between the turbine tip and shroud is reduced, the performance of the turbine in terms of torque and efficiency rises as does the heat transfer from the generator.

\subsection{Other variables' effect on overall performance}

In order to enhance the overall performance of W-T systems, different parameters such as turbine material, mechanics of materials, oscillating chamber and the electricity generation in the system are also investigated.

\subsubsection{Materials and mechanics of materials}

The selection of materials for airfoil blades component is one of the most important issues in the optimum design of W-T employed in an OWC wave power generator as shown in [144]. The selection of materials using Cambridge materials selector [145] and simple tabulation has separated and ranked 5 candidates out of 167 materials class, consisting of Titanium alloys class, GFRP class, and CFRP class. Further evaluation has specified two prime candidates: Fiber Reinforced Composites (Carbon Fiber/Epoxy Resin) and Titanium Alloys (Ti6Al4V).

The authors in [146] describe the methods developed during the design and development phase of its $\mathrm{W}-\mathrm{T}$ suitable for installation into active renewable energy breakwater schemes. Due to the bespoke nature of the systems involved, a finite element analysis is implemented to stress critical components. This piece of information is fed into fatigue analysis routines for component life estimation. The loading, geometry and material models are combined to create a fatigue life prediction. The stresses are then 
added together to give a total stress. The total annual contribution to fatigue from the wave loading is found. This fatigue damage is combined with the damage created from the start-stop cycles to give an overall fatigue life prediction of 44 years.

\subsubsection{Oscillating chamber}

With an additional vertical duct at the wave-beaten side in the of house OWC system, it is expected to give some better performances in [147]. It can be concluded that a U-OWC can give performances better than those of a conventional OWC both with swells and large wind waves. Furthermore, a U-OWC can give performances better than those of a conventional OWC also with small wind waves. In heavy sea states, the conventional OWC is expected to suck air through the opening in the wave-beaten wall, for some short span of time; not so the U-OWC. Under the same weight, a breakwater embodying the U-OWC has a safety factor slightly greater than the safety factor of a breakwater embodying the conventional OWC.

The effects of duct area ratio and duct angle are examined in order to optimize W-T performance in [148]. The turbine performance is numerically investigated by CFD models. The duct area ratio $=1.5$ is considered the optimum area ratio for the investigated turbine as a maximum value of $10 \%$ increase of the turbine power is achieved. Increasing the duct angle to an optimum value of 7degrees at this optimum duct area ratio ensures separation free flow in the downstream diffuser and up to $14 \%$ improvement in turbine power and up to $9 \%$ increase of the turbine efficiency.

\subsubsection{Electricity generation}

Two control strategies of an OWC- W-T generator module are proposed and compared in order to study the stalling behavior in the W-T by [42]. In the first one, a rotational speed control system is employed to appropriately adapt the speed of the double-fed induction generator coupling to the turbine, according to the pressure drop entry. In the second control strategy, an airflow control regulates the power generated by the turbine generator module by means of the modulation valve avoiding the stalling behavior. The experiments suggest that the air control valve is more adequate to regulate the generated power according to the demand of the grid. Therefore, the obtained results 
4 4. W-T comparisons and connections with other 5 turbines

6 Many kinds of self-rectifying air turbines that have improved over the decades are 7 proposed [23, 117, 149-156]. However, a comparison of all of these characteristics has yet to 8 be made. The types of turbines are summarized as follows in Table 5:

Table 5 Self rectifying air turbines for wave energy conversion.

\begin{tabular}{|c|c|c|}
\hline & Type & Remarks \\
\hline $1-$ & \multicolumn{2}{|l|}{ The $W-T$} \\
\hline $1-\mathrm{A})$ & $\begin{array}{l}W-T \text { with guide vanes [157- } \\
159]\end{array}$ & $\begin{array}{l}\text { It was adopted for the project "Mighty Whale" organized by JMSTEC, } \\
\text { Japan }[65,160]\end{array}$ \\
\hline $1-B)$ & $\begin{array}{l}W-T \text { with self-pitch- } \\
\text { controlled blades }[117,121 \text {, } \\
151]\end{array}$ & $\begin{array}{l}\text { The turbine blades can oscillate between two setting angles by themselves } \\
\text { according to the flow direction, where the turbine has active pitch } \\
\text { controlled blades [161]. }\end{array}$ \\
\hline $1-\mathrm{C})$ & $\begin{array}{l}\text { Biplane } W \text {-T with guide } \\
\text { vanes [162] }\end{array}$ & $\begin{array}{l}\text { This type is making progress in Islay, UK [161], where guide vanes are not } \\
\text { used for the turbine. }\end{array}$ \\
\hline $1-\mathrm{D})$ & $\begin{array}{l}\text { Contra-rotating } W-T[16, \\
163]\end{array}$ & $\begin{array}{l}\text { This is installed in the LIMPET system in Islay, UK }[52,164] \text {, which is the } \\
\text { world's first commercial wave power station. }\end{array}$ \\
\hline 2- & \multicolumn{2}{|l|}{ Impulse turbine } \\
\hline $2-\mathrm{A})$ & $\begin{array}{l}\text { Impulse turbine with self- } \\
\text { pitch-controlled guide } \\
\text { vanes }[155,156]\end{array}$ & This turbine has been constructed by NIOT, India [165]. \\
\hline 2- B) & $\begin{array}{l}\text { Impulse turbine with fixed } \\
\text { guide vanes [23] }\end{array}$ & $\begin{array}{l}\text { This is being planned to be constructed in India, China, Korea and Ireland } \\
{[166] .}\end{array}$ \\
\hline 2- C) & $\begin{array}{l}\text { McCormick counter- } \\
\text { rotating turbine [167] }\end{array}$ & $\begin{array}{l}\text { The prototype model of the McCormick turbine was constructed and tested } \\
{[152] \text {. The disadvantage may be the balance of the gearing cost, and its }}\end{array}$ \\
\hline
\end{tabular}




\begin{tabular}{|l||l||l||}
\hline 3- & Radial turbine [153, 154] & noise generation may be a severe problem at specific sites. \\
\hline According to recent research, the efficiency is not so good [168].
\end{tabular}

The characteristics of several types of W-T for wave power conversion proposed so far have been investigated by experimental measurements and numerical simulation under irregular flow conditions in $[20,170]$ at Saga University, see Table 6. It has been found that the impulse type turbines have the potential to be superior to the W-T in overall performances under irregular flow conditions, see Figure 11 (a). Non-dimensional performance curves of the turbines are obtained from model testing, based on the stochastic analysis of the OWC spar buoy wave energy converter in an offshore wave climate [171]. In the simulations, the converter is equipped with various types and sizes of self-rectifying air turbines, namely single-stage and multi-stage W-T and new biradial-impulse turbines $[172,173]$. The results demonstrate that several (possibly four) stages are required for acceptable performance $(67 \%$ efficiency), if a W-T is to be adopted. The new biradial-impulse turbine was found to exhibit an overall device performance (71\% efficiency) better than that of the multi-stage W-T, with the advantage of a substantially smaller rotor diameter without the need for several stages, see Figure 11 (b).

\begin{tabular}{|c|c|c|}
\hline Turbine & Diameter $(\mathbf{m})$ & $\begin{array}{c}\text { Max. efficiency under irregular } \\
\text { flow condition (sea-state) }\end{array}$ \\
\hline Impulse turbine with self-pitch-controlled guide vanes & 0.298 & $\mathbf{4 7 \%}$ \\
\hline W-T with guide vanes & 0.298 & $32 \%$ \\
\hline Impulse turbine with fixed guide vanes & 0.298 & $38 \%$ \\
\hline W-T with self-pitch-controlled blades & 0.298 & $45 \%$ \\
\hline Biplane W-T with guide vanes & $\mathbf{0 . 2 9 8}$ & $\mathbf{3 4 \%}$ \\
\hline
\end{tabular}

An impulse with fixed guide vanes turbine for bi-directional flow is used as the booster turbine in order to improve the efficiency of W-T at high flow coefficient by [26]. The energy 19 from oscillating airflow was captured by W-T at low flow coefficient and the impulse turbine gets the energy at high flow coefficient. The performances of axial flow turbines under steady 
1 flow conditions have been investigated experimentally by model testing. Furthermore, the 2 mean efficiency of the turbine is estimated by quasi-steady analysis in this study. The mean 3 efficiency of the turbine strongly depends on turbine diameter ratio. The mean efficiency at 4 high flow coefficient is improved by means of the impulse turbine as a booster turbine and the 5 peak mean efficiency is lower than that of a single turbine. It can be concluded that it is a new 6 approach to use two different turbines in one system in order to avoid the disadvantages of 7 both turbines. 

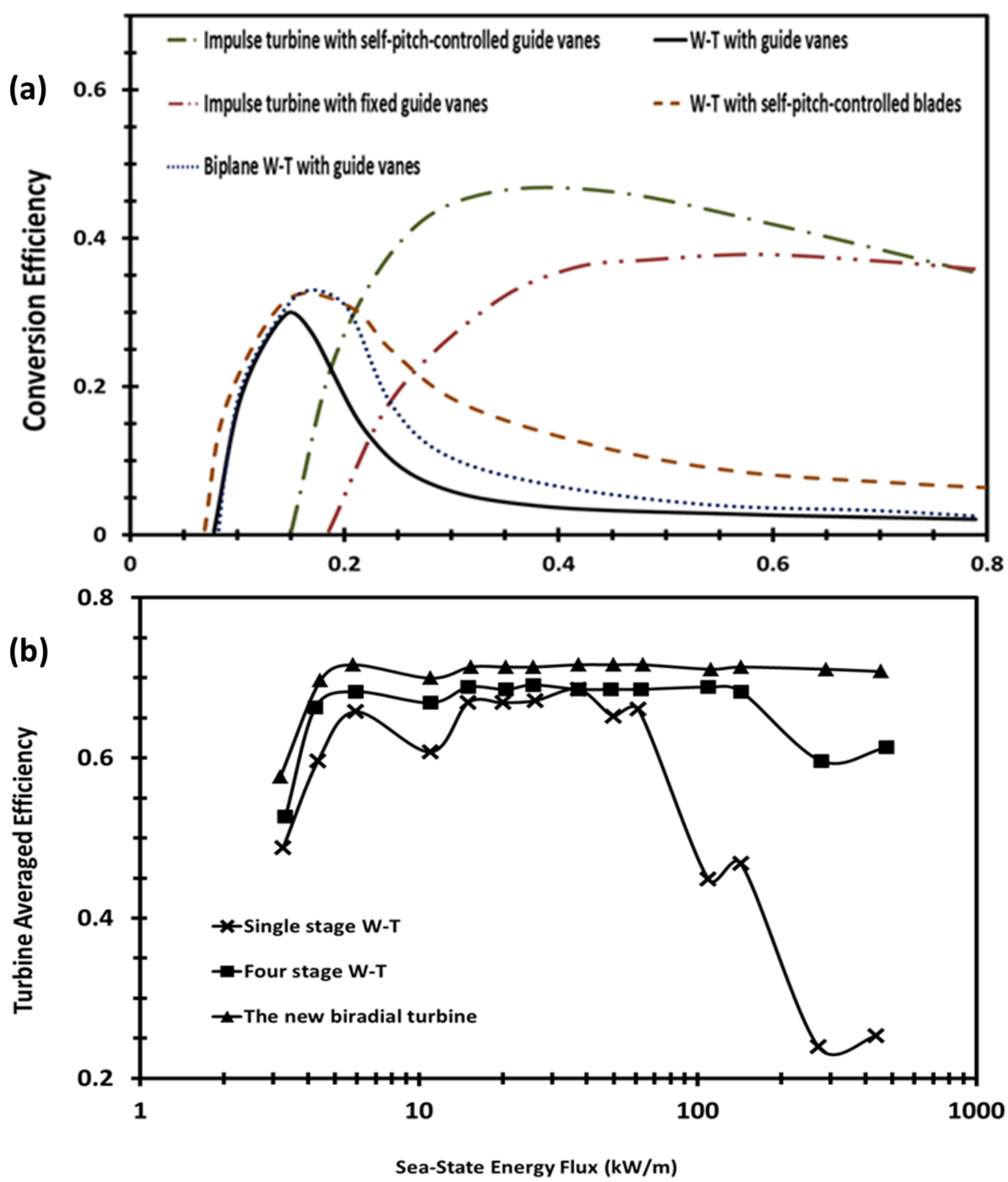

Figure 11 W-T comparisons with other turbines (a) Comparison of conversion efficiency of wave energy under irregular flow condition $[20,170]$ (b) Turbine averaged efficiency versus sea-state energy flux for single/ four stages W-T and for the new biradial turbine [171].

5 5. CFD models of W-T 


\subsection{General description of the flow around W-T}

To the best of the authors' knowledge, there are no published studies about the physics of oscillating flow around $\mathrm{W}-\mathrm{T}$ using laser techniques. It is difficult, therefore, to correlate the published CFD models of such flow physics in order to induce a universally valid description of all flow phenomena. However, there are some phenomena that do exist due to the nature of the oscillating flow behavior as well as to the operational structure of the turbine. There are numerous experimental studies that were conducted using high-resolution measurement techniques, which studied oscillating flow (i.e. oscillating angle of attack) around stationary and moving airfoil for aeronautic applications. Such a flow is similar to the oscillating flow around W-T in the sense of the relationship between oscillating flow interaction with airfoil wall. For a NACA-0012 airfoil subjected to an oscillating flow of frequencyl.67 Hz at an average Reynolds number of $12 \times 10^{3}$, it is found that the flow exhibits manifested vortical flow patterns [174]. Such a study is conducted using Laser Doppler Velocimetry (LDV) and reports the presence of axial flow along the core of the vortices pattern, which complicates the vorticity field. Similar flow patterns for the same airfoil are reported for a higher range of Reynolds number $\left(\operatorname{Re}=10^{5} \sim 2 \times 10^{5}\right)$ and lower frequency $(0.188 \mathrm{~Hz})$ [175]. Hribernik et al. [176] demonstrated by PIV measurements that the separation region (i.e. bubble) generated on a generic airfoil exhibits oscillations under oscillating angle of attack flow. They reported that the separation bubble oscillated around its mean position at an interval of $10 \%$ of the chord length. A similar oscillating behaviour of the separation bubble was reported using LDV measurements, and correlated to dynamic stall conditions of a NACA0012 oscillating airfoil [177]. It was also reported that the flow near the leading edge wall, due to the oscillation of the separation bubble, changes from a jet-like flow to a wake flow. These results were recently confirmed in [178] using PIV measurements of the flow around oscillating NACA0015 airfoil for Reynolds number of $2 \times 10^{5}$ and frequency of up to $0.5 \mathrm{~Hz}$.

It is clear that the oscillating flow around $\mathrm{W}-\mathrm{T}$ is complex. The presence of strong vorticity field, as well as the dynamic behaviour of separation regions, can be easily confirmed by induction of similar flow phenomena in the absence of laser measurements 
of such flows in the time being. Streamline curvature around W-T was also reported by means of numerical simulations [179]. These flow features impose certain critical limitations on the CFD models of W-T, especially in terms of modelled boundary conditions and turbulence models.

\subsection{CFD modeling goals of $\mathrm{W}-\mathrm{T}$}

Given the general operating conditions, air flow around and through W-T can generally be considered an incompressible flow. The Navier-Stokes equation, in conservation form, can be written as:

$\rho \frac{\partial u_{i}}{\partial t}+\rho \frac{\partial}{\partial x_{j}}\left(u_{j} u_{i}\right)=-\frac{\partial p}{\partial x_{i}}+\frac{\partial}{\partial x_{j}}\left(2 \mu s_{j i}\right)$

Where the strain rate tensor is $S_{j i}=\frac{1}{2}\left(\frac{\partial u_{i}}{\partial x_{j}}+\frac{\partial u_{j}}{\partial x_{i}}\right)$.

The modeling of turbulent flow through W-T can be done by solving equation (31) directly on a computational grid with a number of cells in the order of $R e^{\frac{9}{4}}$ [180], which is computationally expensive if one considers rotor optimization simulations. The other two approaches, which are computationally efficient, are either by solving the Reynolds Averaged Navier Stokes (RANS) using a Reynolds stress closure or by solving a filtered Navier-Stokes equation, or by using a hybrid approach that combines the previous two. A discussion of such approaches is presented in section 5.3.

In fact, it is always difficult to decide which turbulence modeling approach to follow in CFD models. However, the consideration of the model essential objectives can be an excellent guideline to make such a decision. The ideal W-T CFD model objectives can be summarized as follows:

1. To provide good prediction of the flow around the turbine so that the performance parameters (such as forces, torque, efficiency... etc.) can be computed.

2. To respond effectively to the changes in the design (i.e. flow geometry) so that different designs can be simulated for optimization purposes. 
When these objectives are considered, the first issue to be discussed is model temporality. A large number of W-T CFD models relied on solutions of the steady averaged Navier-Stokes equation [38, 115, 141, 142]. However, such models are only capable of providing average estimations of the turbine cycle relative to OWC. Models based on the unsteady solution of Navier-Stokes equation are numerous as well, mainly adopting uniform (i.e. sinusoidal) wave form on the boundary as an approximation of the irregular wave forms that exist in nature [93, 181, 182]. Models based on irregular wave forms are relatively scarce in literature records [183, 184], perhaps due to the complexity that irregular boundary conditions impose on the model solution convergence. The use of steady models can be acceptable for preliminary achievement of the first modeling objective. However, given the numerous design details, as shown in sections 3 and 4, and their impact on the flow structure, the use of unsteady models is necessary to complete the first objective, and also the second one. Conservative sinusoidal approximation of irregular wave forms can be accepted for comparing design modifications or different components between two systems. Conservativeness in this context refers to precautions related to the averaging of the frequencies, not just the amplitudes, of the complete irregular wave spectrum. However, to use CFD as a tool for econometric analysis of Wells energy systems, models based on irregular wave forms which emulate the actual wave properties in the potential installation sites should be considered.

\subsection{Turbulence modeling considerations}

The solution of equation (31) in the turbulent flow regime requires an approach for modeling the high nonlinearity arising in the viscous term of the equation. The adoption of Reynolds averaging, which yields the RANS equation, is the most common approach for such purpose. The RANS equation is:

$$
\rho \frac{\partial U_{i}}{\partial t}+\rho U_{j} \frac{\partial U_{i}}{\partial x_{j}}=-\frac{\partial P}{\partial x_{i}}+\frac{\partial}{\partial x_{j}}\left(2 \mu S_{j i}-\rho \overline{u_{j}^{\prime} u_{i}^{\prime}}\right)
$$

The last term on the RHS of equation (32) is called the Reynolds stress term, often denoted as $\tau_{j i}$. This term couples the turbulent fluctuations to the mean flow by assuming that such fluctuations generate additional stresses or produce momentum transport [185]. 
This term is the major problem of turbulence modeling since it requires to be solved in order to compute the mean flow field variables. However, to compute this term, additional equations are required. There are two major methods to provide closure for the Reynolds stress terms in the Navier-Stokes equation, as fully described in [186] and [185]. The first method is by taking the moments of the Navier-Stokes equation. This is achieved by multiplying the equation by a fluctuating property and perform time averaging for the resulting equation [186]. This method leads to the development of second order closures, which include transport equations for all the components of the Reynolds stress term. This is called Reynolds Stress Model. The most common and well tested form of such model is the LRR (Launder, Reece and Rodi) model that was proposed in [187]. The model is composed of one transport equation for $\tau_{j i}$, dissipation rate and pressure-strain correlations, auxiliary relation for the production of $\tau_{j i}$ as well as model coefficients [188]. Although such a model predicts the anisotropic flow field by calculating the components of $\tau_{j i}$, its numerical implementation always faces numerous challenges that make the results of such a model not as accurate as they are theoretically expected. These challenges are thoroughly discussed in [189].

The second method of closure for the Reynolds stress term is the eddy viscosity concept. This concept is based on the work of Boussinesq who postulated that the momentum transfer caused by turbulent eddies is analogous to the momentum transfer caused by the random motion of molecules [190]. A detailed explanation of the Boussinesq hypothesis is given in [186] and in a recent historical discussion presented in [191]. The Boussinesq hypothesis dictates that the Reynolds stress is proportional to the mean strain-rate tensor and the constant of proportionality is the turbulence or eddy viscosity a scalar quantity often denoted as $\left(\boldsymbol{\mu}_{T}\right)$. According to such hypothesis, the Reynolds stress term is given by:

$$
-\rho \overline{u_{i}^{\prime} u_{j}^{\prime}}=\mu_{t}\left(\frac{\partial \bar{u}_{i}}{\partial x_{j}}+\frac{\partial \bar{u}_{j}}{\partial x_{i}}\right)-\frac{2}{3} \delta_{i j}\left(\rho k+\mu_{t} \frac{\partial \bar{u}_{k}}{\partial x_{k}}\right)
$$

The most common turbulence models for engineering applications are based on the eddy viscosity concept. It will be shown later, in section 5.4 that eddy viscosity 
models are the most common class of turbulence models used in modeling W-T. The following section explains some details about these models and their inherited physical assumptions.

\subsubsection{Turbulent viscosity models}

In order to solve equations (32) and (33), additional transport equations for calculating the turbulence scalars (i.e. turbulence kinetic energy, turbulence dissipation rate...etc.) must be solved. There are numerous models for different classes of turbulence flow that solve transport equations for such scalars. Each of these models has inherited physical assumptions that postulate limitations and restrictions on its implementation. The most commonly used turbulence models in the CFD models of W-T are the $k-\varepsilon$ models and $k-\omega$ models. The transport equations for such models can be found in [188]. Each class of these models computes turbulent viscosity via a specific scalar correlation. The following table (Table 7) shows different correlations for the most used eddy viscosity and the variables of each correlation.

Table 7: Eddy viscosity correlation for the most used turbulence models in the W-T CFD models.

\begin{tabular}{|c|c|c|}
\hline Eddy viscosity correlation & Turbulence model & Notes \\
\hline \multirow[t]{2}{*}{$\mu_{t}=\rho C_{\mu} \frac{k^{2}}{\varepsilon}$} & $\begin{array}{l}\text { Standard [192] and } \\
\text { RNG [193] } k-\varepsilon\end{array}$ & $\begin{array}{l}C_{\mu} \text { is an empirical constant, } \mathrm{k} \text { and } \varepsilon \text { are the } \\
\text { turbulence kinetic energy and its dissipation } \\
\text { rate. } C_{\mu} \text { values are } 0.09 \text { and } 0.0845 \text { for the } \\
\text { standard and RNG models, respectively. }\end{array}$ \\
\hline & $\begin{array}{l}\text { Realizable } k-\varepsilon \\
{[194]}\end{array}$ & $\begin{array}{l}\text { Where } C_{\mu} \text { is not constant and given by: } \\
\mathrm{C}_{\mu}=\frac{1}{A_{0}+A_{s} U^{*} \frac{k}{\varepsilon}} \text {, where } A_{0}=4.0 ; U^{*}= \\
\sqrt{S_{i j} S_{i j}+\Omega_{i j} \Omega_{i j}} \\
A_{s}=\sqrt{6} \cos \left(\frac{1}{3} \arccos (\sqrt{6} W)\right) \\
W=\frac{\sqrt{8} S_{i j} S_{j k} S_{k i}}{S^{3}}, \text { and the vorticity tensor is }\end{array}$ \\
\hline
\end{tabular}




\begin{tabular}{|l|l|l|}
\hline & & given by $\Omega_{i j}=\frac{1}{2}\left(\frac{\partial \bar{u}_{i}}{\partial x_{j}}-\frac{\partial \bar{u}_{j}}{\partial x_{i}}\right)$ \\
\hline$\mu_{T}=\rho \frac{k}{\omega}$ & Wilcox original & $\omega$ is the specific dissipation rate of \\
& {$[195]$ and modified } \\
& {$[188] k-\omega$} & turbulence kinetic energy \\
\hline
\end{tabular}

1

Turbulent viscosity models are based on the assumption of isotropic turbulence, which means that these models inherently assume that the components of Reynolds stress tensor equally affect the mean flow in space. This assumption is coherent with Kolmogorov (1941) theory of turbulence [196, 197]. Hence, although the isotropy assumption might lead to an intuition that turbulence viscosity predictions should not be accurate, extensive numerical investigations utilizing these models have yielded successful predictions of complex flows. Examples on the success of eddy viscosity models in predicting different types of vorticity-dominated flow and flow with streamline curvature can be found in [198-209]. LES (Large Eddy Simulation) [210] provides an alternative approach in which the large eddies is computed in a time-dependent simulation that uses a set of filtered equations. Filtering is essentially a manipulation of the exact Navier-Stokes equations to remove only the eddies that are smaller than the size of the filter, which is usually taken as the mesh size. Like Reynolds averaging, the filtering process creates additional unknown terms that must be modeled in order to achieve closure. Statistics of the mean flow quantities, which are generally of most engineering interest, are gathered during the time-dependent simulation. The attraction of LES is that: by modeling less of the turbulence (and solving more), the error induced by the turbulence model will be reduced [211].

It is theoretically possible to directly resolve the whole spectrum of turbulent scales using an approach known as direct numerical simulation (DNS) [212]. Basically, in LES, large eddies are resolved directly while small eddies are modeled. Solving only for the large eddies and modeling the smaller scales results in mesh resolution requirements that are much less restrictive than with DNS. Typically, mesh sizes can be at least one order of magnitude smaller than with DNS [213]. Furthermore, the time step sizes will be proportional to the eddy-turnover time, which is much less restrictive than 
with DNS. In practical terms, however, extremely fine meshes are still required. It is only due to the explosive increase in computer powers that LES can be considered as a possibility for engineering calculations[214, 215]. However, the use of different turbulence models in W-T models requires certain considerations to be made. Some of these considerations are related to the empirical coefficients in the eddy viscosity and turbulence transport equations [216, 217]. Other considerations are related to the suitability of each model to different flow regimes and configurations [218, 219].

\subsection{Review of CFD studies of W-T}

Figures 12(a), (b) and (c) highlight the importance of the CFD method in investigation the studies of the W-T improvement. Figure 12(a) shows a classification of W-T research literature based on the methodology used in each study. It can be conceived that approximately $43 \%$ of the woks used CFD models. Hence, a numerical model using the CFD code can be employed successfully to calculate the performance characteristics of W-T as well as the other methods (such as experimental and analytical). In addition, a number of CFD papers from 1999 to present are introduced in Figure 12 (b). The increase of CFD papers (especially in the last five years) indicates that trend, with large proportion, to depend on the CFD method. Finally, the CFD works are quantitatively categorized in Figure 12 (c). The hysteretic behavior, flow through turbine and TC, has the largest share of CFD modeling works. Due to the difficulty and the high cost of other methods, such as the experimental method, to make bidirectional flow with different operating conditions to study the flow of the hysteretic or of very sensitive and accurate areas such as tip area, the CFD method plays an essential role as evidenced in the research. Figures 12 (a), (b), (c) depend only on the papers that are used in this work. A detailed summary of CFD studies of W-T is given in Table 8. 
(a)

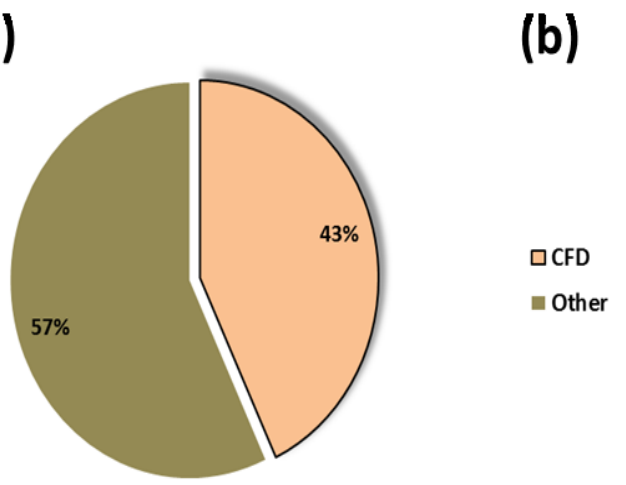

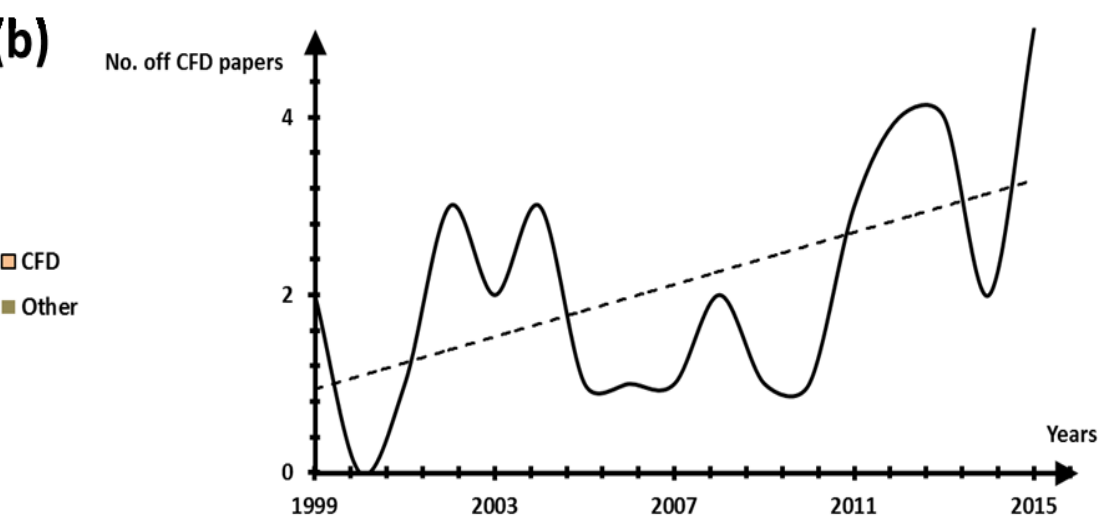

(c)

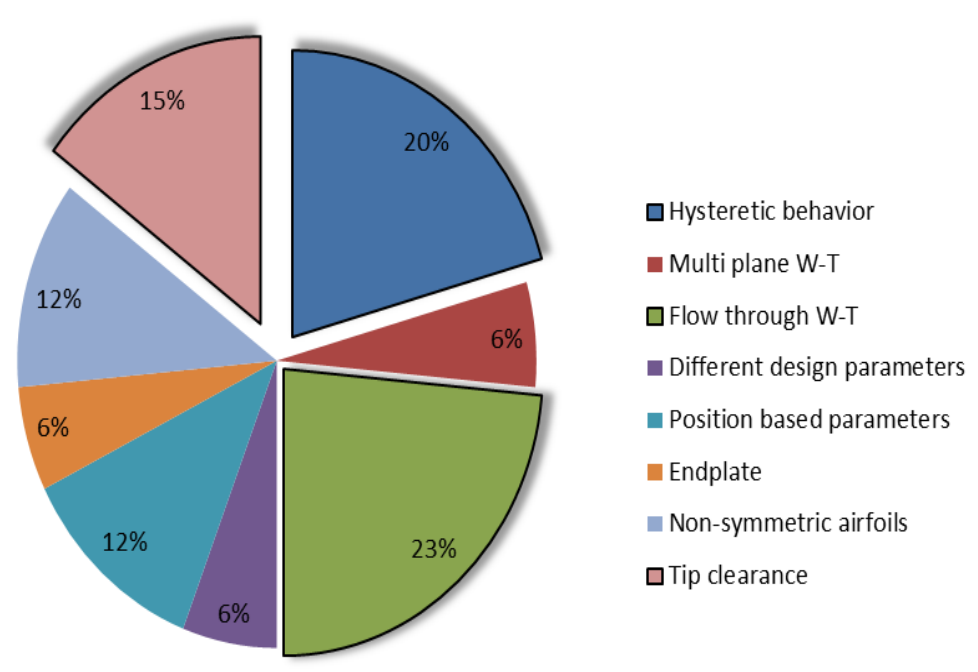

2 Figure 12 Review of CFD studies of W-T (a) the percentage of use to CFD versus with other methods (b) the 3 number of CFD papers in different time period (c) The percentage of use to CFD in all point of research

4 5

Table 8. Detailed summary of CFD studies of W-T

\begin{tabular}{|c|c|c|c|c|c|}
\hline Ref./ Year & Turbulence model & $\begin{array}{c}\text { Reynolds } \\
\text { number }\end{array}$ & $\begin{array}{c}\text { No. of } \\
\text { Elements }\end{array}$ & Blade profile & Boundary Condition \\
\hline$[103] / 1996$ & $\begin{array}{c}\text { K-Epsilon model together with a modified } \\
\text { low Reynolds number model }\end{array}$ & $810^{5}$ & 449,736 & NACA0015 & 3D-Unsteady \\
\hline$[112] / 1997$ & $\begin{array}{c}K \text {-Epsilon model together with a modified } \\
\text { low Reynolds number model }\end{array}$ & $810^{5}$ & 436,000 & NACA0015 & $3 \mathrm{D}-$ Unsteady \\
\hline$[132] / 2001$ & RNG K-Epsilon model & $510^{5}$ & 80000 & CA9 & $3 \mathrm{D}-$ Steady \\
\hline
\end{tabular}




\begin{tabular}{|c|c|c|c|c|c|}
\hline$[78] / 2002$ & $K$-Epsilon model & -NA- & 400,000 & $\begin{array}{l}\text { NACA0012, } \\
\text { NACA0015, } \\
\text { NACA0021 }\end{array}$ & $\begin{array}{l}\text { 3D-Unsteady-(Time step }=0.001 \text { sec- } \\
\text { sinusoidal wave) }\end{array}$ \\
\hline$[115] / 2002$ & $K$-Epsilon model with a modification model & $\begin{array}{c}\text { Low Reynolds } \\
\text { number }\end{array}$ & 70,000 nodes & $\begin{array}{l}\text { NACA0020, } \\
\text { CA9 }\end{array}$ & 3D-Steady \\
\hline$[79] / 2002$ & RNG-SGS model & $2.410^{5}$ & 560,000 & $\begin{array}{l}\text { NACA0015, } \\
\text { NACA0020 }\end{array}$ & $\begin{array}{c}\text { 3D-Unsteady-( } f=0.167 \text { - one-half period of } \\
\text { the sinusoidal wave })\end{array}$ \\
\hline$[83] / 2003$ & RNG-SGS & $2.410^{5}$ & 560,000 & NACA0020 & $\begin{array}{c}\text { 3D-Unsteady- }(f=0.167 \text { - one-half period of } \\
\text { the sinusoidal wave })\end{array}$ \\
\hline$[80] / 2003$ & RNG-SGS model & $2.410^{5}$ & 560,000 & $\begin{array}{l}\text { NACA0020, } \\
\text { NACA0015 }\end{array}$ & 3D-Unsteady ( $f=0.167$ - sinusoidal wave) \\
\hline$[84] / 2004$ & large eddy simulation- RNG-SGS model & $2.410^{5}$ & $\begin{array}{c}560,000 \\
\text { (monopla)- } \\
720,000 \\
\text { (biplane) }\end{array}$ & NACA0020 & $\begin{array}{l}\text { 3D-Unsteady-( } f=0.167 \text {-half period of the } \\
\text { sinusoidal wave })\end{array}$ \\
\hline$[85] / 2004$ & LES and RNG-SGS model & $2.410^{5}$ & $\begin{array}{c}560,000 \\
\text { (monoplane) - } \\
720,000 \\
\text { (biplane) }\end{array}$ & NACA0020 & $\begin{array}{l}\text { 3D-Unsteady-( one-half period of the } \\
\text { sinusoidal-) }\end{array}$ \\
\hline$[94] / 2004$ & K-Omega SST & 539233 & 163840 & NACA0015 & $\begin{array}{c}\text { 3D-steady (Two sinusoidal wave- } 0.8 \text { and } 1.2 \\
\mathrm{~m} \text { wave height- } 2.275 \text { and } 3.413 \mathrm{~m} / \mathrm{s} \text { axial } \\
\text { velocity) }\end{array}$ \\
\hline$[104] / 2005$ & K-Epsilon model & -NA- & 620,000 & NACA 0021 & 3D-steady \\
\hline$[130] / 2006$ & $K$-Epsilon model. & $\begin{array}{c}\text { From } 1.010^{5} \\
\text { to } \\
3.810^{5}\end{array}$ & $\begin{array}{l}560,000 \\
\text { and } 580,000\end{array}$ & $\begin{array}{l}\text { NACA0020 } \\
\text { with endplate }\end{array}$ & 3D-Steady \\
\hline$[131] / 2007$ & RNG- K-Epsilon model & $2.510^{5}$ & 570,000 & $\begin{array}{l}\text { NACA0020 } \\
\text { with endplate }\end{array}$ & 3D-Steady \\
\hline$[101] / 2008$ & SST model & $2.410^{5}$ & 25600 & $\begin{array}{l}\text { (AOP) based on } \\
\text { NACA } 2421\end{array}$ & 2D-Steady \\
\hline$[38] / 2008$ & Spalart Allmaras & -NA- & 1092352 & NACA0015 & 3D-Steady \\
\hline$[37] / 2009$ & Spalart Allmaras, K-Omega SST & $210^{5}$ & $210^{6}, 2.410^{6}$ & NACA0015 & 3D-Steady \\
\hline
\end{tabular}




\begin{tabular}{|c|c|c|c|c|c|}
\hline & & & and $4.110^{6}$ & & \\
\hline$[141] / 2010$ & Realizable $K$-Epsilon & $\begin{array}{l}\text { From } 0.7410^{5} \\
\text { to } 4.4110^{5}\end{array}$ & 295,500 & NACA0020 & 3D-Steady \\
\hline [39] / 2011 & k-SST model & $\begin{array}{c}\text { From } 34833 \text { to } \\
42199\end{array}$ & $410^{6}$ & NACA0015 & 3D-Steady \\
\hline$[136] / 2011$ & Realizable $K$-Epsilon & $2.410^{5}$ & $\begin{array}{l}\text { between } 60,000 \\
\text { and } 80,000\end{array}$ & $\begin{array}{l}\text { NACA 0021, } \\
\text { (AOP) }\end{array}$ & 2D-Steady \\
\hline$[142] / 2011$ & Realizable $K$-Epsilon & $\begin{array}{c}\text { From } 0.6810^{5} \\
\text { to } 4.4110^{5}\end{array}$ & 295,500 . & NACA0020 & 3D-Steady \\
\hline$[108] / 2012$ & Realizable $K$-Epsilon & -NA- & 424686. & NACA 0021 & 3D-Steady \\
\hline$[220] / 2012$ & SST transitional model & 120000 & $3.510^{6}$ (nodes) & NACA 0021 & 3D-Unsteady $\left(\right.$ time-step $\left.=5 \quad 10^{-5}\right)$ \\
\hline$[102] / 2012$ & $\begin{array}{c}\text { Realizable } K \text {-Epsilon model and the } \\
\text { Reynolds stress }\end{array}$ & -NA- & $1,236,576$ & NACA0015 & 3D-Steady \\
\hline$[148] / 2012$ & Realizable $K$-Epsilon model & -NA- & $1,131,540$ & NACA0015 & 3D-Steady \\
\hline$[143] / 2013$ & K-Omega SST & $\begin{array}{c}\text { From } 1.410^{5} \\
\text { to } 2.810^{5}\end{array}$ & -NA- & NACA0020 & 3D-Steady \\
\hline$[128] / 2013$ & Realizable $K$-Epsilon turbulence model & $2.410^{5}$ & $60000-80000$ & $\begin{array}{l}\text { NACA0021, } \\
\text { (AOP) }\end{array}$ & 2D-Steady \\
\hline$[129] / 2013$ & Realizable $K$-Epsilon turbulence model & 2. $10^{4}$ & $\begin{array}{l}\text { 2D- } 60,000 \text { and } \\
\quad 80,000 \\
\text { 3D-1,348,760 } \\
\text { and } 1,404,690 \\
\text { for(AOP) }\end{array}$ & $\begin{array}{l}\text { NACA0021, } \\
\text { AOP }\end{array}$ & 3D-2D-Steady \\
\hline [116] / 2013 & $\begin{array}{l}\text { Standard fully turbulent shear-stress } \\
\text { transport turbulence model }\end{array}$ & $5.010^{5}$ & $1.810^{6}$ & $\begin{array}{c}\text { Hub: } \\
\text { NACA0018-63 } \\
\text { Midspan: } \\
\text { NACA0015-63 } \\
\text { Tip: } \\
\text { NACA0012-63 }\end{array}$ & 3D- Steady \\
\hline$[221] / 2013$ & SST-turbulence model & $5.410^{5}$ & 1.8 million & $\begin{array}{c}\text { Hub: } \\
\text { NACA0021-63 } \\
\text { Mid: }\end{array}$ & 3D- Steady \\
\hline
\end{tabular}




\begin{tabular}{|c|c|c|c|c|c|}
\hline & & & & $\begin{array}{l}\text { NACA0018-63 } \\
\text { Tip: } \\
\text { NACA0015-63 }\end{array}$ & \\
\hline$[111] / 2014$ & Realizable $K$-Epsilon model & $\begin{array}{l}\text { From } 610^{4} \text { to } \\
410^{5}\end{array}$ & 312951 & $\begin{array}{c}\text { NACA0012, } \\
\text { NACA0015, } \\
\text { NACA0020 and } \\
\text { NACA0021 }\end{array}$ & 2D-Steady \\
\hline [137] / 2015 & RNG- K-Epsilon model & -NA- & $\begin{array}{c}238,876 \text { and } \\
207,638\end{array}$ & $\begin{array}{l}\text { NACA0020 and } \\
\text { variable chord } \\
\text { airfoil }\end{array}$ & 3D- Steady \\
\hline$[222] / 2015$ & K-Omega SST & -NA- & $1,424,016$ & NACA0015 & 3D- Steady \\
\hline$[223] / 2015$ & K-Omega SST & -NA- & -NA- & Modified blade & 3D- Steady \\
\hline$[224] / 2015$ & Transition SST model & $\begin{array}{c}\text { From } \\
0.810^{5} \text { to } \\
1.510^{5}\end{array}$ & NA & NACA 0015 & 3D-Unsteady- $\mathrm{T}=9 \mathrm{sec}$ \\
\hline$[225] / 2015$ & K-Omega SST & $1,368,000$ & $1,424,016$ & NACA0015 & 3D- Steady \\
\hline$[27] / 2016$ & Realizable $K$-Epsilon model & $\begin{array}{l}\text { From } 610^{4} \text { to } \\
410^{5}\end{array}$ & 312951 & $\begin{array}{l}\text { NACA0012, } \\
\text { NACA0015, } \\
\text { NACA0020 and } \\
\text { NACA0021 }\end{array}$ & 2D-Unsteady- $\mathrm{T}=6.7 \mathrm{sec}$ \\
\hline
\end{tabular}

1

$2 \quad 5.5$ Validation of CFD models

3 The most validation cases are cited for self-rectifying W-T that are performed at Saga

4 University in Japan[77, 226]. The experimental work is done at a test rig capable of producing

5 reversing air flows. The flow is produced by the reciprocating motion of a piston in a large

6 cylinder (1.4m diameter, $1.7 \mathrm{~m}$ long) [73, 227]. The piston can be driven back and forth by means

7 of three ball screws acted upon by a DC servomotor. A computer controls the motor to produce

8 any air flow velocity. A settling chamber is located between the cylinder and the $300 \mathrm{~mm}$

9 diameter turbine test section. Many of CFD investigations employ this experimental work as a

10 validation case such as T.H. Kim, et al. [79, 115] and Zahari Taha, et al. [141, 142], in addition

11 to several other CFD works in [80, 84, 85, 131, 136, 137]. 
Other experimental works that are also often used as validation cases can be found in

2 [100]. A larger rig was constructed in 1992 at Instituto Superior Técnico, Lisbon, where W-T (rotor diameter $0.6 \mathrm{~m}$ ) was tested in a unidirectional flow. The turbine pressure drops and air flow rates are supplied by a centrifugal fan fitted with a variable-speed controller. The turbines were mounted in an open-ended annular duct that led to a plenum chamber. The chamber contained a honeycomb lattice that straightened the air flow entering the calibrated nozzle (both designed according to AMCA 210/67 standard), which was situated upstream of the exhaust outlet. The $0.67 \mathrm{~m}$ long nozzle contracted from 0.8 to $0.4 \mathrm{~m}$ while the plenum chamber was $2 \mathrm{~m}$ long, $1.72 \mathrm{~m}$ high and $1.78 \mathrm{~m}$ wide. The turbines were connected via a torque meter to a motorgenerator whose speed could be varied continuously. The double-shaft turbines were fitted with an extra bearing assembly, torque and speed transducer, and a generator for the upstream rotor. These experimental work data can be found in many validation cases such as Paresh Halder, et al. [222, 223, 225] and S. Shaaban [102, 148], as well as M. Torresi, et al. [38, 94].

The breakwater built in the natural laboratory of Reggio Calabria (at Politecnico di Bari University -DIMeG Department) was $16.3 \mathrm{~m}$ long, and it is realized by nine caissons close to each other[96]. Each caisson consists of three interconnected cells, where air can flow from one cell to another of the same caisson through holes. The central caisson is equipped with a small scale prototype of $\mathrm{W}-\mathrm{T}$, placed in a duct connected to the central cell of the caisson. The turbine hub is made up of aluminum and is obtained from a commercial fan. The blades have been produced with composite material reinforced by carbon fiber with suited attachment[228, 229]. In addition to the experimental work, M. Torresi and S. M. Camporeale implemented the CFD method to examine the performance of $\mathrm{W}-\mathrm{T}$ in $[37,39]$. delivering the necessary pneumatic power to the W-T [104, 230, 231]. The blower is capable of developing an optimum static pressure rise of about $2000 \mathrm{~N} / \mathrm{m}^{2}$, while delivering a discharge of $1.1 \mathrm{~m}^{3} / \mathrm{s}$. The delivery duct of the centrifugal blower is $2800 \mathrm{~mm}$ long and has a diameter of 250 mm. A diverging cone of length $25 \mathrm{~mm}$ connects this duct with the turbine test section. The validation result can be found in Z. Carija, et al. [108] and T.S. Dhanasekaran, et al. [104].

The experimental setup was carried out on a turbine enclosed in a cylindrical annular duct, with an axial flow fan mounted at the exit of the duct [179]. The turbine was mechanically 
1 connected to an electric generator/motor by a belt drive. Turbine rotors were tested with 4, 6 and

28 blades of constant chord. The blades were made of fiberglass with a good surface finish. Tip

3 clearance was about $1 \mathrm{~mm}$. The rotor hub was a disk whose axial length at the periphery was 50

$4 \mathrm{~mm}$. In the 4- and 6-bladed configurations, the turbine was found to be unable to reach full

5 rotational speed on its own as a consequence of its net torque being negative or too small at

6 intermediate speeds. The electrical machine was then used as a motor for starting purposes. J. K.

7 Watterson, et al. used these experimental data to validate their CFD work in [112].

The most recent experimental setup was done by the Department of Mechanical, 9 Chemical and Materials Engineering of the University of Cagliari (DIMCM). This work can 10 simulate the real operation of a wave energy conversion device based on the principle of an 11 (OWC) equipped with a W-T [110, 232]. Wave motion is reproduced by means of a piston 12 moving inside a chamber generating the periodic bi-directional airflow through the turbine. The 13 turbine drives a three-phase induction machine controlled by an inverter with encoder feedback. 14 The wave characteristics - defined by the shape, amplitude and frequency of the piston motion 15 can be modified by adjusting the parameters of the hydraulic control unit to obtain a maximum 16 flow velocity in the range of $10-20 \mathrm{~m} / \mathrm{s}$. The set-up is instrumented with different sensors 17 allowing measurement of torque, angular velocity, piston position as well as static pressure, total 18 pressure and flow direction upstream and downstream of the rotor with aerodynamic probes. The 19 flow field characteristics are measured by introducing aerodynamic probes in the sections located 20 upstream and downstream of the turbine at a distance of about $20 \mathrm{~mm}$ from the impeller. This 21 experimental work is also used as a validation case by T. Ghisu, et al. in [224]. Table 9 22 demonstrates the geometric details for six experimental works that were often used for the CFD 23 validation cases.

Table 9 Geometric Details for CFD Validation Cases

\begin{tabular}{|c|c|c|c|c|c|c|c|c|}
\hline $\begin{array}{c}\text { Validation } \\
\text { Case }\end{array}$ & $\begin{array}{c}\text { Blade } \\
\text { profile }\end{array}$ & $\mathbf{C}$ & $\boldsymbol{R}_{h}$ & $\mathbf{Z}$ & $\boldsymbol{\sigma}$ & $\boldsymbol{R}_{t}$ & $\begin{array}{c}\text { Reynolds } \\
\text { number }\end{array}$ & Note \\
\hline $\begin{array}{c}{[73,77,226} \\
227]\end{array}$ & NACA0020 & $90 \mathrm{~mm}$ & $104.5 \mathrm{~mm}$ & 6 & 0.67 & $149 \mathrm{~mm}$ & $2.410^{5}$ & Aspect ratio $=0.5$ \\
\hline
\end{tabular}




\begin{tabular}{|c|c|c|c|c|c|c|c|c|}
\hline [100] & NACA 0015 & $125 \mathrm{~mm}$ & $200 \mathrm{~mm}$ & 8 & 0.64 & $294 \mathrm{~mm}$ & $\begin{array}{c}6.510^{5} \text { and } \\
3.910^{5}\end{array}$ & $\begin{array}{l}\text { Tip clearance of } \\
\quad 1 \mathrm{~mm} \\
\text { Angular velocity } \\
=2000 \mathrm{rpm}\end{array}$ \\
\hline $\begin{array}{c}{[96,228,} \\
229]\end{array}$ & NACA 0015 & $74 \mathrm{~mm}$ & $101 \mathrm{~mm}$ & 7 & 0.64 & $155 \mathrm{~mm}$ & $210^{5}$ & $\begin{array}{l}\text { Tip clearance }= \\
2 \% \text { from chord } \\
\text { length }\end{array}$ \\
\hline $\begin{array}{c}{[104,230,} \\
231]\end{array}$ & NACA 0021 & $100 \mathrm{~mm}$ & $81.5 \mathrm{~mm}$ & 4 & 0.6 & $131.5 \mathrm{~mm}$ & -NA- & $\begin{array}{l}\text { Tip clearance of } \\
\quad 1 \mathrm{~mm} \\
\text { Angular velocity } \\
=4500 \mathrm{rpm}\end{array}$ \\
\hline [179] & NACA 0012 & $100 \mathrm{~mm}$ & $150 \mathrm{~mm}$ & $\begin{array}{l}4,6 \\
\text { and } 8\end{array}$ & $\begin{array}{l}0.29,0.44 \\
\text { and } 0.59\end{array}$ & $296.5 \mathrm{~mm}$ & $5.610^{5}$ & $\begin{array}{c}\text { Rotational speed } \\
=2700 \mathrm{rpm} \\
\text { Tip Mach number } \\
0.25\end{array}$ \\
\hline$[110,232]$ & NACA 0015 & $36 \mathrm{~mm}$ & $95 \mathrm{~mm}$ & 14 & 0.729 & $125 \mathrm{~mm}$ & $\begin{array}{c}\text { Between } 0.8 \\
10^{5} \text { and } 1.510^{5}\end{array}$ & $\begin{array}{c}\text { Piston Period } \\
\text { between } 7 \text { and } 9 \mathrm{~s}\end{array}$ \\
\hline
\end{tabular}

\section{6. Discussion}

3 Over 230 studies are investigated in this work. By collecting data about its main

4 methodology, we can classify the role of CFD in each research parameter. Guide vanes before

5 and after the rotor may be one of the most effective devices to improve turbine performance.

6 However, literature records do not show any CFD studies of guide vanes. For the hysteretic

7 behavior, it can be concluded that several parameters have effects on the performance of $\mathrm{W}-\mathrm{T}$ in

8 bi-directional airflow, but the most important one appears to be the hysteresis effect. Figure

9 13(1) shows the use of CFD compared to experimental measurement in studying hysteretic 10 behavior.

11 The multi plane $\mathrm{W}-\mathrm{T}$ is required to improve the performance, and especially the contra-rotating

12 one. The CFD method appears in recent research (for this section) to yield more accurate results. 
In addition, we can improve the performance of W-T by investigating the flow-field through the

2 turbine and its parts by studying the flow characteristics at different operating conditions, such as Reynolds number, Mach number, flow coefficient, angle of attack and flow direction, and also by studying the stall condition, the starting behavior and the Tip leakage flow effect. More than $65 \%$ of the above studies depend on the CFD method to predict the behavior of the flow through the turbine, even in the nineties, see Figure 13 (2).

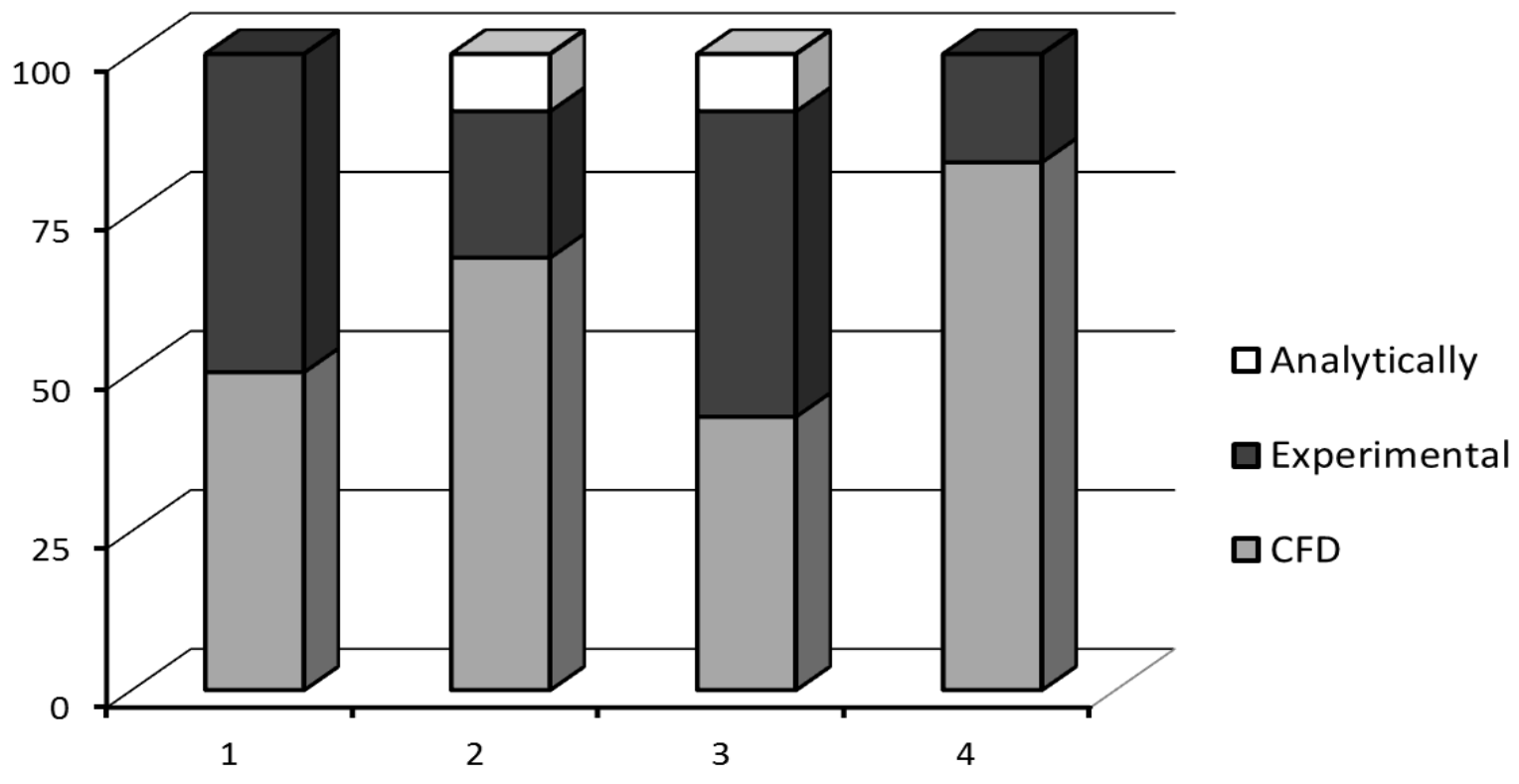

Figure 13 (1) Classification of research: fifteen papers discussing the Hysteretic Behaviour according to the main methodology of each paper. (2) Classification of research: thirteen papers discussing the Flow through turbine according to the main methodology of each paper. (3) Classification of research: twenty four papers discussing the Design Optimization according to the main methodology of each paper. (4) Classification of research: seven papers discussing the TC according to the main methodology of each paper.

The design optimization section includes four parts; it can be concluded from this part that the most important parameters effect on the performance of $\mathrm{W}-\mathrm{T}$ is the turbine blade solidity. Blade thicknesses, hub to tip ratio and the size of turbine also have effects on the performance of $\mathrm{W}-\mathrm{T}$. The change in previous parameters to improve the performance is the basic step to design optimization, so most of this research is conducted in the eighties and the nineties, and therefore the CFD method has a very modest effect. The position of blade, according to the hub centerline, has a direct effect on the performance of turbines, and it is shown in the second part of position-based parameters. Setting the blades at their optimum pitch angle during compression and suction is expected to substantially improve W-Ts' efficiency. It is clear that there is a tendency to the CFD method in recent research in addition to taking an important role 
1 in the formation of the optimization code. Moreover, the peak efficiency of W-T increases by

2 attaching endplate to its blade.

Finally, the non-symmetric airfoils, in an attempt by the researchers to improve the

4 overall performance of turbine, non-traditional airfoil, are investigated. CA9, HSIM 15-262123-

51576 and other optimum airfoil have been used to achieve this purpose. As a conclusion for

6 Design Optimization with its four parts, the CFD method has been used in all parts from the

7 nineties till now to complete the experimental work in an easier and a cheaper way, see Figure 13

8 (3). In addition, it gives very promising results in terms of increasing the overall turbine

9 performance, especially the optimum shape part. Therefore, there is a need to conduct more

10 investigation and to use other different methods for optimization. In other words, design

11 optimization is the key for future study.

13 The studies underline the importance of the optimization of the TC in order to improve the 14 turbine performance in terms of torque coefficient and efficiency, because of the sensitivity of 15 W-T to TC. The effect of TC on the W-T system was ascertained long time ago, but no method 16 is like the CFD to investigate this phenomenon; therefore, more than $80 \%$ of the studies use the 17 CFD method. In addition, the increased possibilities and the development of CFD method 18 increase the study and understanding of this phenomenon, see Figure 13 (4).

When W-T is compared to the impulse turbine, the latter has a higher overall performance. But this point will be discussed in details in the next part. The experimental and numerical simulation analysis is used to investigate in this issue. 


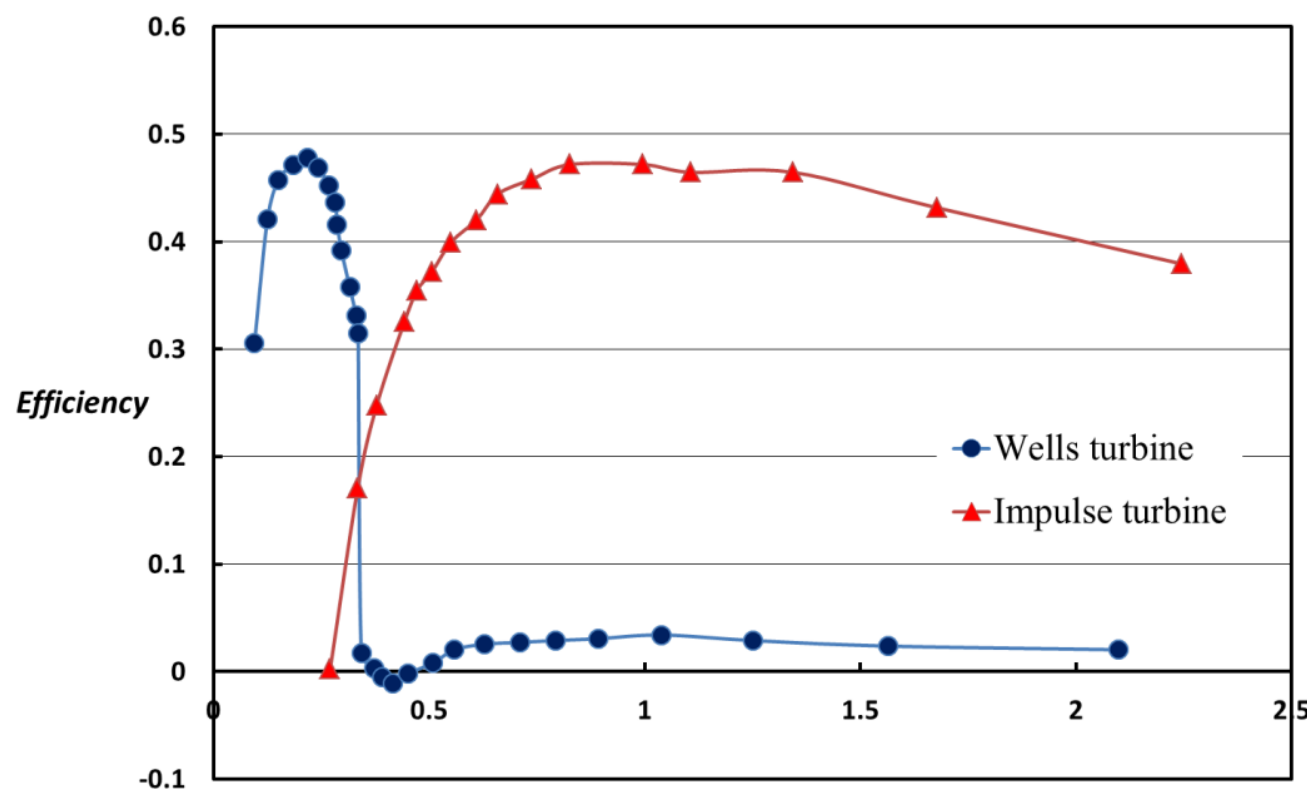

Flow Coefficient

Figure 14 Turbines characteristics under steady flow conditions: Flow coefficient variation with the efficiency [26]

In view of the previous research in the section of the connections with other turbines, it can be concluded that the efficiency of W-T is higher than that of the impulse turbine when the flow coefficient is less than the stall point. But after the stall point of $\mathrm{W}-\mathrm{T}$, the efficiency of the impulse turbine is considerably higher than that of W-T. In other words, W-T can extract power at a low air flow rate, when other turbines would be inefficient, as shown in Figure 14. In addition, it is relatively cheap to construct.

\section{Conclusion}

A comprehensive review for the $\mathrm{W}-\mathrm{T}$ is presented in this paper. The literature references are categorized according to the research approaches to different W-T components, and according to the research methods investigating W-T. Since CFD is a widely used approach in W-T research, an independent section of the review is devoted to comparatively discuss the methods and techniques. The following remarks can be concluded from the review:

- W-T components play vital roles in performance and efficiency. Each component requires a rigorous optimization practice to harvest possible additional efficiency enhancement. 
- Guide vanes and multi stage of W-T that have the same direction of rotation are used to increase the efficiency; in addition, the two-stage W-T has an opposite direction.

- The increase in Reynolds number, Mach number, flow coefficient and angle of attack leads to an increase in the efficiency of W-T, until a certain critical value.

- Determining the optimum position of endplate and the optimum value of blade sweep ratio, TC, blade skew and setting pitch angle increases the efficiency of W-T. However, the numerical optimization process is used to create optimum non-symmetric airfoil.

- The use of W-T in low flow coefficient period and impulse turbine in high flow coefficient period increases the overall performance of OWC system.

- The global entropy generation rate due to viscous dissipation is a very sensitive indicator for W-T behavior at any change in design parameters, the operating condition and also being affected by flow direction.

\section{Acknowledgements}

The authors would like to acknowledge the support provided by the Department of Naval Architecture, Ocean and Marine Engineering at Strathclyde University, UK and the Department of Marine Engineering at Arab Academy for Science, Technology and Maritime Transport, Alexandria, Egypt.

\section{References}

[1] IEA. Medium-Term Renewable Energy Market Report 2014 : Market Analysis and Forecasts to 2020. International Energy Agency; 2014. p. 260.

[2] Bogart WT, Morriss AP, Meiners RE, Dorchak A. The Challenge of Green Energy. The False Promise of Green Energy. U.S.A.: Cato Institute; 2011. p. 47-72.

[3] Feasibility of Developing Wave Power as Renewable Energy Resource for Hawaii. Honolulu: Department of Business, Economic Development and Tourism; 2002.

[4] Mamun M. The Study on the Hysteretic Characteristics of the Wells Turbine in a Deep Stall Condition [PhD]. Japan: Saga University; 2006.

[5] Cruz J. OceanWave Energy: springer; 2008.

[6] Falcão AFdO. Wave energy utilization: A review of the technologies. Renewable and Sustainable Energy Reviews. 2010;14:899-918.

[7] Twidell J, Weir T. Renewable Energy Resources. Second edition ed: Taylor \& Francis; 2006. [8] Marimuthu C, Kirubakaran V. A CRITICAL REVIEW OF FACTORS AFFECTING WIND TURBINE AND SOLAR CELL SYSTEM POWER PRODUCTION. International Journal of Advanced Engineering Research and Studies. 2014:143-7.

[9] Masters GM. Wind Power Systems. Renewable and Efficient Electric Power Systems: John Wiley \& Sons, Inc.; 2004. p. 307-84.

[10] Johnson GL. Wind Turbine Power. Wind Energy Systems2001. 
[11] Rosa AVd. Fundamentals of Renewable Energy Processes. Third Edition ed: Elsevier Academic Press; 2012.

[12] T. J. T. Whittaker JGL, A. E. Long and M. A. Murray. The Queen's university of Belfast Axisymmetric and Multi-resonant Wave Energy Converters. Trans ASME J Energy Resources Tech. 1985;107: pp. 74-80. [13] T. J. T. Whittaker FAM. Design Optimisation of Axisymmetric Tail Tube Buoys. IUTAM, Symposium on Hydrodynamics of Ocean Wave Energy Conversion. Lisbon,July.1985.

[14] Whittaker TJJ, Mcllwain, S. T. and Raghunathan, S. . Islay Shore Line Wave Power Station. Proceedings European Wave Energy Symposium. 1993;Paper G6, Edinburgh.

[15] Raghunathan S. Theory and Performance of Wells Turbine. Queen's University of Belfast. 1980;Rept. WE/80/13R.

[16] Raghunathan S. The Wells Air Turbine for Wave Energy Conversion. Progress Aerospace Sciences. 1995;31:335-86.

[17] Curran R, M. Folley Air turbine design for OWCs. In: Cruz iJ, editor. Ocean Wave Energy. Springer, Berlin. 2008. p. 189-219.

[18] Falcão AFO, Gato LMC. Air Turbines. In: Sayigh AA, editor. Comprehensive Renewable Energy Ocean Energy, Elsevier,Oxford . 2012. p. 111-49.

[19] Starzmann R. Aero-acoustic Analysis of Wells Turbines for Ocean Wave Energy Conversion [Doctoral ]. Germany: Universitat Siegen; 2012.

[20] Setoguchi T, Takao M. Current status of self rectifying air turbines for wave energy conversion. Energy Conversion and Management. 2006;47:2382-96.

[21] Dixon SL. Fluid Mechanics, Thermodynamics of Turbomachinery: Pergamon Press Ltd; 1998.

[22] IA B. Apparatus for Converting Sea Wave Energy into Electrical Energy. US Patent 3,922,739 1975;2 December 1975.

[23] Setoguchi T TM, Kinoue Y, Kaneko K, Santhakumar S, Inoue M. . Study on an impulse turbine for wave energy conversion. International Journal Offshore Polar Eng. 2000;10:145-52.

[24] T. Setoguchi SS, H. Maeda, M. Takao and K. Kaneko. A Review of Impulse Turbine for Wave Energy Conversion. Renewable Energy. 2001;23:261-92.

[25] T. Setoguchi MT, S. Santhakumar and K. Kaneko. Study of an Impulse Turbine for Wave Power Conversion: Effects of Reynolds Number and Hub-to-Tip Ratio on Performance. Journal of Offshore Mechanics and Arctic Engineering. 2004;126:137-40.

[26] Okuhara S, Takao M, Takami A, Setoguchi T. Wells Turbine for Wave Energy Conversion Improvement of the Performance by Means of Impulse Turbine for Bi-Directional Flow. Open Journal of Fluid Dynamics. 2013;03:36-41.

[27] Shehata AS, Saqr KM, Xiao Q, Shehadeh MF, Day A. Performance Analysis of Wells Turbine Blades Using the Entropy Generation Minimization Method. Renewable Energy33-86:1123;2016 ..

[28] SHERMAN ENJaA. Airfoil section characteristics as affected by variation of the Reynolds number. NACA Rep. 1937; No. 586.

[29] Sheldahl RE, Klimas PC. Aerodynamic Characteristics of Seven Symmetrical Airfoil Sections Through 180-Degree Angle of Attack for Use in Aerodynamic Analysis of Vertical Axis Wind Turbines. Sandia National Laboratories energy report. the United States of America1981. p. 118.

[30] Raghunathan S, Tan CP, Wells NAJ. Wind Tunnel Tests on Airfoils in Tandem Cascade. AIAA Journal. 1981;19:1490-2.

[31] Wolfe WP, Ochs SS. Predicting Aerodynamic Characteristics of Typical Wind Turbine Airfoils Using CFD. SANDIA REPORT. the United States of America1997. p. 41.

[32] Gareev A, Kosasih B, Cooper P. Analysis of interference factors of air turbine cascades. Engineering Applications of Computational Fluid Mechanics. 2013;7:496-506.

[33] Weinig FS. Theory of two-dimensional flow through cascades. In: Hawthorne WR, editor. Aerodynamics of Turbines and Compressors, Oxford University Press, London 1964. p. 13-82. 
[34] Scholz N. Aerodynamics of Cascades. AGARD-AG-220: NATO Science and Technology Organization; 1978. p. 611.

[35] Csanady GT. Theory of turbomachines. First ed. London.: McGraw-Hill; 1964.

[36] Horlock JH. Axial Flow Compressors. First ed. Oxford: Butterworths scientific publications; 1958.

[37] Torresi M, Camporeale SM, Pascazio G. Detailed CFD Analysis of the Steady Flow in a Wells Turbine Under Incipient and Deep Stall Conditions. Journal of Fluids Engineering. 2009;131:071103.

[38] Torresi M, Camporeale SM, Strippoli PD, Pascazio G. Accurate numerical simulation of a high solidity Wells turbine. Renewable Energy. 2008;33:735-47.

[39] Torresi M, D. Pranzo, S.M. Camporeale, Pascazio G. Improved Design of High Solidity Wells Turbine. the Ninth European Wave and Tidal Energy Conference (EWTEC2011). Southampton, UK2011.

[40] Prado M, Polinder H. Direct drive wave energy conversion systems: an introduction. 2013:175-94.

[41] Bose BK. Modern Power Electronics and AC Drives: Prentice-Hall, Inc.; 2002.

[42] Amundarain M, Alberdi M, Garrido AJ, Garrido I, Maseda J. Wave energy plants: Control strategies for avoiding the stalling behaviour in the Wells turbine. Renewable Energy. 2010;35:2639-48.

[43] McCormick RBaME. Wave Energy Conversion Elsevier, Ocean Engineering Series. 2003;6:1-187.

[44] Alain Cle'ment PM, Anto'nio Falca o,, Antonio Fiorentino FG, Karin Hammarlund,, George Lemonis TL, Kim Nielsen,, Simona Petroncini M-TP, Phillippe Schild,, Bengt-Olov Sjo“stro"m HCS, Thorpe T. Wave energy in Europe: current status and perspectives. Renewable and Sustainable Energy Reviews.

2002;6:405-31.

[45] Webb I, Seaman C, Jackson G. Marine Energy Challenge Oscillating Water Column Wave Energy Converter Evaluation Report. 2005. p. 196.

[46] Suzuki M AC, and Takahashi S. Performance of wave power generating system installed in breakwater at Sakata port in Japan. the 14th International Offshore Polar Engineering Conference, Mountain View, CA, USA. Toulon, France: In: Chung JS; 2004. p. 202-9.

[47] Jayakumar; Neelamani SR, V.S. An experimental investigation of wave forces on an oscillating water column type wave energy caisson. European Wave Energy Symposium1993.

[48] VS R, M R, PM K. Experiences on a $150 \mathrm{~kW}$ wave energy pilot plant. In: G EGaC, editor. European Wave Energy Symposium, East Kilbride, Scotland. Edinburgh, UK.1993. p. 277-82.

[49] TV H. The development of a turbo-generation system for application in OWC breakwaters. In: AFO F, editor. the 7th European Wave Tidal Energy Conference. Porto, Portugal.2007.

[50] Torre-Enciso Y, Ortubia I, Aguileta LILd, Marqués J. Mutriku Wave Power Plant: from the thinking out to the reality. The 8th European Wave and Tidal Energy Conference. Uppsala, Sweden2009. p. 31929.

[51] Teillant MV, G.P. Rosati Papini, G. Moretti, R. Vertechy, M. Fontana, K. Monkand, M. Alves. Technoeconomic comparison between air turbines and dielectric elastomer generators as power take off for oscillating water column wave energy converters. 11th European Wave \& Tidal Energy Conference. Nantes, France.2015.

[52] Boake CB, Whittaker TJT, Folley M, Ellen H. Overview and Initial Operational Experience of the LIMPET Wave Energy Plant. The Twelfth International Offshore and Polar Engineering Conference. Kitakyushu, Japan: The International Society of Offshore and Polar Engineers; 2002. p. 586-94.

[53] Whittaker TJTM, S.J. \& Raghunathan, S. A review of Islay shoreline wave power plant. European Wave Energy Symposium. 1993.

[54] Heath T. Islay LIMPET project monitoring, ETSU V/06/00180/00/Rep, Dti Pup URN No 02/1435. 2002.

[55] Wavegen. Research into the further development of the LIMPET shoreline wave energy plant, Dti, V/06/00183/00/Rep. 2002. 
[56] Heath T, Whittaker, T.J.T \& Boake, C.B. The design, construction and operation of the LIMPET wave energy converter. In: S Olal, editor. the 4th European Wave Energy Conference, Danish Technological Institute, Denmark. Aalborg, Denmark.2000. p. 49-55.

[57] Belfast TQsUo. Islay LIMPET Wave Power Plant, Non-nuclear Energy Programme Joule III, CORDIS, JOR3-CT98-0312. 2002.

[58] Falcao AFdS, M.; Whittaker, T.J.T. \& Lewis, A.W. Design of a shoreline wave power plant for the island of Pico, Azores. 1995.

[59] Falcao AFd. The shoreline OWC wave power plant at the Azores. Wave Energy 20002000.

[60] Falcao AFdOJ, P.A.P. OWC wave energy devices with air flow control. Ocean Engineering. 1999;26:

1275-95.

[61] Falcao AFd. Control of an oscillating-water-column wave power plant for maximum energy production. Applied Ocean Research. 2003;24:73-82.

[62] Falcao AFd. Stochastic Modelling in wave power-equipment optimisation: maximum energy production versus maximum profit. Ocean Engineering. 2004.

[63] Falcao AFd. Control of an oscillating-water-column wave power plant for maximum energy production. Applied Ocean Research 242002. p. 73-82.

[64] Thorpe TW. An Assessment of The Art OSPREY Wave Energy Device, ETSU-R-90, Dti. 1995.

[65] Washio Y OH, Nagata Y, et al. The offshore floating type wave power device 'Mighty Whale': Open sea tests. In: JS C, editor. the 10th International Offshore Polar Engineering Conference, Mountain View, CA, USA. Seattle, WA, USA.2000. p. 373-80.

[66] S R, R C, TJT W. Performance of the Islay Wells air turbine. the Institution of Mechanical Engineers, Part A: Journal of Power and Energy. 1995;209:55-62.

[67] C.E.TINDALL, XU M. Optimising a Wells-turbine-type wave energy system. IEEE Transactions on Energy Conversion. 1996;11:631 - 5.

[68] Whittaker TJT, Stewart TP, Curran R. Design synthesis of oscillating water column wave energy converters: performance matching. Proceedings of the Institution of Mechanical Engineers, Part A: Journal of Power and Energy. 1997;211:489-505.

[69] Jayashankar V, Udayakumar K, B.Karthikeyan, Manivannan K, Venkatraman N, Rangaprasad S. Maximizing Power Output from A Wave Energy Plant. Power Engineering Society Winter Meeting, 2000 IEEE: IEEE; 2000. p. 1796 - 801.

[70] Folley M, Curran R, Whittaker T. Comparison of LIMPET Contra-rotating Wells Turbine with Theoretical and Model Test Predictions. Ocean Engineering. 2006;33:1056-69.

[71] Raghunathan S. A methodology for Wells turbine design for wave energy conversion. ARCHIVE: Proceedings of the Institution of Mechanical Engineers, Part A: Journal of Power and Energy 1990-1996 (vols 204-210). 1995;209:221-32.

[72] Setoguchi T, Santhakumar S, Takao M, Kim TH, Kaneko K. Effect of Guide Vane Shape on the Performance of a Wells Turbine. Renewable Energy. 2001;23:1-15.

[73] Takao M, Setoguchi T, Kim TH, Kaneko K, Inoue M. The Performance of a Wells Turbine with 3D Guide Vanes. International Journal of Offshore and Polar Engineering. 2001;11:72-6.

[74] Brito-Melo A, Gato LMC, Sarmento AJNA. Analysis of Wells turbine design parameters by numerical simulation of the OWC performance. Ocean Engineering. 2002;29:1463-77.

[75] Masami Suzuki, Arakawa C. Design Method of Wave Power Generating System with Wells Turbine. Twelfth InternationalOffshoreandPolarEngineeringConference. Kitakyushu,Japan: The International Society of Offshore and Polar Engineers; 2002. p. 527-33.

[76] Gato LMC, Henriques, J.C.C. Optimization of symmetrical profiles for Wells turbine rotor blades. Proceedings of the ASME Fluids Engineering Division Summer Meeting, . 1996;FED-238:623-30.

[77] Setoguchi T TM, Kaneko K. Hysteresis on Wells Turbine Characteristics in Reciprocating Flow. International Journal of Rotating Machinery. 1998;4:17-24. 
[78] Tae-Hun Kim, Yeon- Won Lee, III-Kyoo Park, Toshiaki Setoguchi, Kang C-S. Numerical Analysis for Unsteady Flow Characteristics of the Wells Turbine. International Offshore and Polar Engineering Conference. Kitakyushu, Japan: The International Society of Offshore and Polar Engineers; 2002. p. 6949.

[79] Kim TH, Setoguchi T, Kinoue Y, Kaneko K, Inoue M. Hysteretic Characteristics of Wells Turbine for Wave Power Conversion. The Twelfth International Offshore and Polar Engineering Conference. Kitakyushu, Japan: The International Society of Offshore and Polar Engineers; 2002. p. 687-93. [80] Setoguchi T, Kinoue Y, Kim TH, Kaneko K, Inoue M. Hysteretic Characteristics of Wells Turbine for Wave Power Conversion. Renewable Energy. 2003;28:2113-27.

[81] Kinoue Y, Setoguchi T, Kuroda T, Kaneko K, Takao M, Thakker A. Comparison of Performances of Turbines for Wave Energy Conversion. Journal of Thermal Science. 2003;12:323-8.

[82] Setoguchi T, Takao M, Itakura K, Mohammad M, Kaneko K, Thakker A. Effect of Rotor Geometry on the Performance of Wells Turbine. The Thirteenth International Offshore and Polar Engineering Conference. Honolulu, Hawaii, USA: The International Society of Offshore and Polar Engineers; 2003. p. 374-81.

[83] Kinoue Y, Setoguchi T, Kim TH, Kaneko K, Inoue M. Mechanism of Hysteretic Characteristics of Wells Turbine for Wave Power Conversion. Journal of Fluids Engineering. 2003;125:302.

[84] Kinoue Y, Kim TH, Setoguchi T, Mohammad M, Kaneko K, Inoue M. Hysteretic Characteristics of Monoplane and Biplane Wells Turbine for Wave Power Conversion. Energy Conversion and Management. 2004;45:1617-29.

[85] Mamun M, Kinoue Y, Setoguchi T, Kim TH, Kaneko K, Inoue M. Hysteretic Flow Characteristics of Biplane Wells Turbine. Ocean Engineering. 2004;31:1423-35.

[86] Ericsson LEaR, J.P. Fluid Dynamics of Unsteady Separated Flow, Part II. Lifting Surface. Prog Aerospace Sci. 1987;24:249-356.

[87] CRIMI P, YAGGY, P. F. Dynamic stall. In: AGARD-AG-172, editor.: Advisory Group for Aerospace Research and Development (North Atlantic Treaty Organisation); 1972.

[88] McCroskey WJ. "Some Unsteady Separation Problems for Slender Bodies," , No94, p8-1: AGARD Lecture Series; 1980.

[89] McCroskey WJ. "Prediction of Unsteady Separated Flows on Oscillating Airfoils," AGARD Lecture Series, No.94, p. 12-1.; 1980.

[90] Shida Y, Kuwahara, K, Ono, K. and Takami, H. Computation of Dynamic Stall of a NACA-0012 Airfoil. AIAA Journal. 1987;25:408-13.

[91] Carr LW. Progress in Analysis and Prediction of Dynamic Stall. J Aircraft. 1988;25:6-17.

[92] Thakker A, Abdulhadi R. Effect of Blade Profile on the Performance of Wells Turbine under Unidirectional Sinusoidal and Real Sea Flow Conditions. International Journal of Rotating Machinery. 2007;2007:1-9.

[93] Thakker A, Abdulhadi R. The Performance of Wells Turbine Under Bi-Directional Airflow. Renewable Energy. 2008;33:2467-74.

[94] TORRESI M, CAMPOREALE SM, PASCAZIO G, FORTUNATO B. Fluid Dynamic Analysis of a Low Solidity Wells Turbine. Atti del 59 Congresso Annuale ATI. Genova, Italy2004. p. 277-88.

[95] Camporeale SM, Filianoti P, Torresi M. Performance of a Wells turbine in a OWC device in comparison to laboratory tests. the Ninth European Wave and Tidal Energy Conference (EWTEC). Southampton, UK2011.

44 [96] Camporeale SM, Filianoti P. Behaviour of a small Wells turbine under randomly varying oscillating 45 flow. the 8th European Wave and Tidal Energy Conference EWTEC. Uppsala, Sweden2009. p. 690-6.

46 [97] Gato LMC, Curran R. Performance of the Contrarotating Wells Turbine. International Journal of 47 Offshore and Polar Engineering. 1996;6:68-75. 
[98] Raghunathan S, Beattie WC. Aerodynamic performance of contra-rotating Wells turbine for wave energy conversion. ARCHIVE: Proceedings of the Institution of Mechanical Engineers, Part A: Journal of Power and Energy 1990-1996 (vols 204-210). 1996;210:431-47.

[99] Curran R, Whittaker TJT, Raghunathan S, Beattie WC. Performance Prediction of Contrarotating Wells Turbines for Wave Energy Converter Design. Journal of Energy Engineering. 1998;124:35-53. [100] Gato LMC, Curran R. The Energy Conversion Performance of Several Types of Wells Turbine Designs. Proceedings of the Institution of Mechanical Engineers, Part A: Journal of Power and Energy. 1997;211:133-45.

[101] Mohamed MH, Janiga G, Th'evenin D. Performance Optimization of a Modified Wells Turbine using Non-Symmetric Airfoil Blades. Turbo Expo 2008: Power for Land, Sea and Air GT. Berlin, Germany: ASME; 2008.

[102] Shaaban S. Insight Analysis of Biplane Wells Turbine Performance. Energy Conversion and Management. 2012;59:50-7.

[103] Watterson JK, Raghunathan S. INVESTIGATION OF WELLS TURBINE PERFORMANCE USING 3-D CFD. INTERSOCIETY ENERGY CONVERSION ENGINEERING CONFERENCE(IECEC 96). Washington, DC: IEEE; 1996. p. $1777-82$.

[104] Dhanasekaran TS, Govardhan M. Computational Analysis of Performance and Flow Investigation on Wells Turbine for Wave Energy Conversion. Renewable Energy. 2005;30:2129-47.

[105] S. Raghunathan CPT, and N. A. J. Wells. Theory and Performance of a Wells Turbine. J Energy. 1987;6:157-60.

[106] L. M. C. Gato aAFdOF. On the Theory of the Wells Turbine Trans. ASME: J Eng Gas Turbines Power. Trans1984. p. 628-33.

[107] Horlock JH. Actuator disk theory. London: McGraw-Hill International Book Co.; 1978.

[108] Carija Z, Kranjcevic L, V.Banic, M.Cavrak. NUMERICAL ANALYSIS OF WELLS TURBINE FOR WAVE POWER CONVERSION. Engineering Review. 2012;32:141-6.

[109] Zorović D, Mohović R, Mohović Đ. Toward Determining the Length of the Wind Waves of the Adriatic Sea. Naše more. 2003;50:3-4.

[110] Paderi M, Puddu P. Experimental investigation in a Wells turbine under bi-directional flow. Renewable Energy. 2013;57:570-6.

[111] Shehata AS, Saqr KM, Shehadeh M, Xiao Q, Day AH. Entropy Generation Due to Viscous Dissipation around a Wells Turbine Blade: A Preliminary Numerical Study. Energy Procedia. 2014;50:808-16.

[112] Watterson JK, Gillan MA, Raghunathan S, Mitchell RD. APPLICATIONS OF COMPUTATIONAL FLUID DYNAMICS TO A WAVE ENERGY CONVERSION DEVICE. INTERSOCIETY ENERGY CONVERSION ENGINEERING CONFERENCE(IECEC 97). Honolulu, HI: IEEE; 1997. p. 1976 - 81.

[113] Curran R. Ocean Wave Energy Systems Design: Conceptual Design Methodology for the Operational Matching of the Wells Air Turbine. the 15th ISPE International Conference on Concurrent Engineering Belfast, Northern Ireland: Springer London; 2008. p. 601-15.

[114] Gato LMC, Webster M. An experimental investigation into the effect of rotor blade sweep on the performance of the variable-pitch Wells turbine. Journal of Power and Energy. 2001;215 Part A:611-22. [115] Kim TH, Setoguchi T, Kaneko K, Raghunathan S. Numerical investigation on the effect of blade sweep on the performance of Wells turbine. Renewable Energy. 2002;25:235-48.

[116] Starzmann R, Carolus T. Effect of Blade Skew Strategies on the Operating Range and Aeroacoustic Performance of the Wells Turbine. Journal of Turbomachinery. 2013;136:011003.

[117] Inoue M, Kaneko, K, Setoguchi T, and Hamakawa, H Air turbine with self-pitch-controlled blades for wave power generator (Estimation of performances by model testing). JSME International Journal. 1989;Ser II, 32:19-24.

[118] Salter S. Variable Pitch Air Turbines," Proc Euro Wave Energy Symp, Edinburgh, pp 435-442. Symposium of European Wave Energy. Edinburgh1993. p. 435-42. 
[119] Sarmento AJNA GL, and FalcZo AfdeO Wave-Energy Absorption by an OWC Device with BladePitch-Controlled Air-Turbine. Proc 6th Int Offshore Mechanics and Arctic Eng Symp, ASME. 1987;2:46573.

[120] Setoguchi T, Raghunathan, S, Takao, M, and Kaneko, K. Air-Turbine with Self-Pitch-Controlled Blades for Wave Energy Conversion (Estimation of Performances in Periodically Oscillating Flow). Int Journal Rotating Machinery. 1997;3:233-8.

[121] Takao M, Setoguchi, T, Kaneko, K, and Inoue, M. Air Turbine with Self-Pitch-Controlled Blades for Wave Energy Conversion. Int Journal Ofihore and Polar Eng, ISOPE. 1997a;7:308-12.

[122] Takao M, Setoguchi, T, Santhaknmar, S, and Kaneko, K. A Comparative Study of Turbines Using Pitch-Controlled Blades for Wave Energy Conversion. Proc 2nd Int Symp Fluid Mechanics and Heat Transfer. Dhaka1997b. p. 243-50.

[123] Vakalis IS SA. Real-time control of OWC with a variable pitch-angle turbine. Proceedings of the Fourth European Wave Energy Conference. Denmark2000. p. 309-18.

[124] Thakker T FP, Bajeet ES. . CA9: analysis of a stall-resistant aerofoil in view of wave power conversion. Proceedings of the 11th International Offshore and Polar Engineering Conference. Stavanger, Norway2001. p. 614-23.

[125] M. Takao, Lee YW. Air Turbine Using Self-Pitch-Controlled Blades for Wave Energy Conversion. Twelfth International Offshore and Polar Engineering Conference. Kitakyushu, Japan: The International Society of Offshore and Polar Engineers; 2002. p. 668-73.

[126] Setoguchi T, Santhakumar S, Takao M, Kim TH, Kaneko K. A modified Wells turbine for wave energy conversion. Renewable Energy. 2003;28:79-91.

[127] Taylor JRM, Caldwell NJ. Design and Construction of the variable-pitch air-turbine for the Azores wave energy plant. Third European Wave Power Conference. Patras, Greece 1998 p. 328-37.

[128] Mohamed MH, Shaaban S. Numerical Optimization of Axial Turbine with Self-pitch-controlled Blades used for Wave Energy Conversion. International Journal of Energy Research. 2014;38:592-601. [129] Mohamed MH, Shaaban S. Optimization of Blade Pitch Angle of an Axial Turbine Used for Wave Energy Conversion. Energy. 2013;56:229-39.

[130] Mamun M, Kinoue Y, Setoguchi T, Kaneko K, Islam AKMS. Improvement af the Performance of the Wells Turbine by using a Very Thin Elongated Endplate at the Blade Tip. the 3rd BSME-ASME International Conference on Thermal Engineering. Dhaka, Bangladesh: ASME; 2006.

[131] Takao M, Setoguchi T, Kinoue Y, Kaneko K. Wells Turbine with End Plates for Wave Energy Conversion. Ocean Engineering. 2007;34:1790-5.

[132] Thakker A, Frawley P, Bajeet ES. Numerical Analysis of Wells Turbine Performance Using a 3D Navier Stokes Explicit Solver. International Offshore and Polar Engineerbtg Conference. Stavanger, Norway2001.

[133] Thakker A, Frawley P, Bajeet ES, Heffernan A. Experimental Investigation of CA9 Blades on a 0.3m Wells Turbine Rig. the Tenth (2000) International Offshore and Polar Engineering Conference. Seattle, USA: International Society of Offshore and Polar Engineers; 2000. p. 345-50.

[134] THAKKER A, FRAWLEY P, DALY J, ABUGHAILIA Y. A 2D CFD study of symmetrical airfoils. PART II: in cascade flow. Cupertino, CA, ETATS-UNIS: International Society of Offshore and Polar Engineers; 2000.

[135] Takao M, Thakker A, Abdulhadi R, Setoguchi T. Effect of Blade Profile on the Performance of a Large-scale Wells Turbine for Wave-energy Conversion. International Journal of Sustainable Energy. 2006;25:53-61.

44 [136] Mohamed MH, Janiga G, Pap E, Thévenin D. Multi-objective Optimization of the Airfoil Shape of 45 Wells Turbine used for Wave Energy Conversion. Energy. 2011;36:438-46.

46 [137] Soltanmohamadi R, Lakzian E. Improved design of Wells turbine for wave energy conversion using 47 entropy generation. Meccanica. 2015. 
[138] Inoue M, Kaneko, K., Setoguchi, T. and Raghunathan, S. The fundamental characteristics and future of Wells turbine for wave power generator. Science of Machines. 1987;39:275-80.

[139] Raghunathan S, Setoguchi, T. and Kaneko, K. Aerodynamics of monoplane Wells turbine-A review. Offshore mechanics and Polar Engineering Conference. Edinburgh, U.K.1991.

[140] Tagori R, Arakawa, C. and Suzuki, M. Estimation of prototype performance and optimum design of Wells turbine. Research in Natural Energy SPEY 20. 1987:127-32.

[141] Taha Z, Sugiyono, Sawada T. A comparison of computational and experimental results of Wells turbine performance for wave energy conversion. Applied Ocean Research. 2010;32:83-90.

[142] Taha Z, Sugiyono, Tuan Ya TMYS, Sawada T. Numerical investigation on the performance of Wells turbine with non-uniform tip clearance for wave energy conversion. Applied Ocean Research.

2011;33:321-31.

[143] Ahmed N, Mueller M. Impact of varying clearances for the Wells turbine on heat transfer from electrical generators in oscillating water columns. Eighth International Conference and Exhibition on Ecological Vehicles and Renewable Energies (EVER). Monte Carlo, Monaco2013.

[144] Saptono R. Selection of Materials for the Aerofoil Blades of a Wells Turbine Operated in an Oscillating Water Column (OWC) Wave Power Station. 2004.

[145] Ltd. GD. Cambridge selection software: CMS. Cambridge1995.

[146] Tease WK, Lees J, Hall A. Advances in Oscillating Water Column Air Turbine

Development. the 7th European Wave and Tidal Energy Conference (EWTEC 2007). Porto,

Portugal2007.

[147] Boccotti P. Comparison between a U-OWC and a conventional OWC. Ocean Engineering. 2007;34:799-805.

[148] Shaaban S, Abdel Hafiz A. Effect of duct geometry on Wells turbine performance. Energy Conversion and Management. 2012;61:51-8.

[149] Akabane M SH, Yamauchi K. On the cross flow turbine for wave power plant. Proceedings of the 1st Symposium on wave energy utilization in Japan. 1984.

[150] Katsuhara M KF, Kajiwara K, Ohta Y. Characteristics of air turbines for wave activated generator used as light beacon. Proceedings of 2 nd symposium on wave energy utilization in Japan, JAMSTEC. 1987:83-91.

[151] Kim TH ST, Kaneko K, Takao M. The optimization of blade pitch settings of air turbine using selfpitch-controlled blades for wave power conversion. Journal Solar Energy Eng. 2001;123:382-6.

[152] Richard D WJF. Studies with, and testing of the McCormick pneumatic wave energy turbine with some comments on PWECS systems. Proceedings of international symposium on utilization of ocean waves-wave to energy conversion ASCE. 1986:80-102.

[153] McCormick ME RJ, Williams BD. An experimental study of a bidirectional radial turbine for pneumatic energy conversion. Proceedings of mastering the oceans through technology. 1992;2:866-70. [154] McCormick ME CB. A performance study of a bi-directional radial turbine. Proceedings of the European wave energy symposium, Edinburgh, UK. 1993:443-8.

[155] Setoguchi T KK, Maeda H, Kim TW, Inoue M. Impulse turbine with self-pitch-controlled guide vanes for power conversion: performance of mono-vane type. International Journal Offshore Polar Eng. 1993;3:73-8.

[156] Setoguchi T KK, Taniyama H, Maeda H, Inoue M. . Impulse turbine with self-pitch-controlled guide vanes connected by links. International Journal Offshore Polar Eng. 1996;6:76-80.

[157] Gato LMC FoAdO. Performance of Wells turbine with double row of guide vanes. JSME International Journal (Ser II) 1990;33:262-71.

[158] Inoue M KK, Setoguchi T. Studies on Wells turbine for wave power generator (part 3; effect of guide vanes). B JSME. 1985;28:1986-91. 
[159] Setoguchi T TM, Kaneko K, Inoue M. . Effect of guide vanes on the performance of aWells turbine for wave energy conversion. International Journal Offshore Polar Eng. 1998;8:155-60.

[160] Miyazaki T WY, Hotta, H. Utilization of coastal seas by floating wave energy device 'mighty whale'. Proceedings of the European wave energy symposium, Edinburgh, UK. 1993:373-8.

[161] Falcao AFdeO WT, Lewis AW. JOULE II preliminary action: European pilot plant study. Proceedings of the European wave energy symposium, Edinburgh, UK. 1993:247-57.

[162] Setoguchi T KK, Matsuki E, Hamakawa H, Inoue M. . Some techniques to improve the performance of biplane Wells turbine for wave power generator. Proceedings of the 1st Pacific/Asia offshore mechanics symposium. Seoul, Korea1990. p. 207-12.

[163] Beattie WC RS. A novel contra rotating Wells turbine. Proceedings of the European wave energy symposium, Edinburgh, UK. 1993:191-6.

[164] Alcorn RG BW. Power quality assessment from the LIMPET wave-power station. Proceedings of the 11th international offshore and polar engineering conference ISOPE, Stavanger, Norway, June 17-22. 2001;1:575-80.

[165] S. S. Report of workshop on turbine for ocean energy application. Indian Institute of Technology, Madras, India. 1996.

[166] Thakker A FP, Khaleeq HB. . Private communication with wave energy research team. University of Limerick, Ireland. 1999.

[167] ME. M. Ocean wave energy conversion. New York: Wiley-Interscience. 1981:142-9.

[168] Setoguchi T SS, Takao M, Kaneko K. . A performance study of a radial turbine for wave energy conversion. Journal of Power Energy 2002;216:15-22.

[169] Kaneko K ST, Raghunathan S. . Self-rectifying turbine for wave energy conversion. Proceedings of the 1st offshore and polar engineering conference, ISOPE, Edinburgh, UK, August 11-16, 1991.

1991;1:385-92.

[170] Kim T-H, Takao M, Setoguchi T, Kaneko K, Inoue M. Performance comparison of turbines for wave power Conversion. International journal of thermal science 2001;40:681-9.

[171] Falcão AFO, Henriques JCC, Gato LMC, Gomes RPF. Air turbine choice and optimization for floating oscillating-water-column wave energy converter. Ocean Engineering. 2014;75:148-56.

[172] Falcão AFO, Gato LMC, Nunes EPAS. A novel radial self-rectifying air turbine for use in wave energy converters. Renewable Energy. 2013;50:289-98.

[173] Falcão AFO, Gato LMC, Nunes EPAS. A novel radial self-rectifying air turbine for use in wave energy converters. Part 2. Results from model testing. Renewable Energy. 2013;53:159-64.

[174] Koochesfahani MM. Vortical patterns in the wake of an oscillating airfoil. AIAA journal. 1989;27:1200-5.

[175] Berton E, Favier D, Maresca C, Benyahia A. Flow field visualizations around oscillating airfoils. Report UMSR. 2002;2164.

[176] Hribernik A, Fike M, Bombek G, Hribersek M. EXPERIMENTAL INVESTIGATION OF AN UNSTEADY FLOW FIELD AROUND AN AIRFOIL. XX IMEKO World Congress, Metrology for Green Growth Busan, Republic of Korea

[177] Chandrasekhara M, Ahmad S. Laser velocimetry measurements of oscillating airfoil dynamic stall flow field. AIAA 22nd Fluid Dynamics, Plasma Dynamics \& Lasers Conference: DTIC Document; 1991. [178] Sharma DM, Poddar K. Investigation of dynamic stall characteristics for flow past an oscillating airfoil at various reduced frequencies by simultaneous PIV and surface pressure measurements. PIV13; 10th International Symposium on Particle Image Velocimetry, Delft, The Netherlands, July 1-3, 2013: Delft University of Technology; 2013.

[179] Gato LMC, Falcao AFO. Aerodynamics of the Wells Turbine. International Journal of Mechanical Sciences. 1988;30:383-95.

48 [180] Wilcox DC. Turbulence Modeling for CFD: DCW Industries; 1998. 
[181] Nunes G, Valério D, Beirão P, Sá da Costa J. Modelling and control of a wave energy converter. Renewable Energy. 2011;36:1913-21.

[182] Sefoguchi T, Kinoue Y, Mohammad M, Kaneko K, Takao M. Unsteady flow phenomena of wells turbine in deep stall condition. Proceedings of the International Offshore and Polar Engineering Conference2004. p. 266-71.

[183] Maeda H, Setoguchi T, Takao M, Sakurada K, Kim TH, Kaneko K. Comparative study of turbines for wave energy conversion. Journal of Thermal Science. 2001;10:26-31.

[184] Takao M, Setoguchi T. Air turbines for wave energy conversion. International Journal of Rotating Machinery. 2012;2012.

[185] Davidson PA. Turbulence: an introduction for scientists and engineers: Oxford University Press; 2004.

[186] Wilcox DC. Turbulence Modeling for CFD. Glendale, California, USA: Griffin Printing; 1994.

[187] Launder B, Reece GJ, Rodi W. Progress in the development of a Reynolds-stress turbulence closure. Journal of fluid mechanics. 1975;68:537-66.

[188] Wilcox DC. Turbulence Modeling for CFD: DCW Industries; 2006.

[189] Piquet J. Turbulent Flows: Models and Physics: Springer Berlin Heidelberg; 2013.

[190] Boussinesq J. Théorie de l'Écoulement Tourbillant. Mem Présentés par Divers Savants Acad Sci Inst Fr. 1877;23:46-50.

[191] Schmitt FG. About Boussinesq's turbulent viscosity hypothesis: historical remarks and a direct evaluation of its validity. Comptes Rendus Mécanique. 2007;335:617-27.

[192] Launder B, Sharma B. Application of the energy-dissipation model of turbulence to the calculation of flow near a spinning disc. Letters in heat and mass transfer. 1974;1:131-7.

[193] Yakhot V, Orszag S, Thangam S, Gatski T, Speziale C. Development of turbulence models for shear flows by a double expansion technique. Physics of Fluids A: Fluid Dynamics (1989-1993). 1992;4:1510-

20.

[194] Shih T-H, Liou WW, Shabbir A, Yang Z, Zhu J. A new k- $\epsilon$ eddy viscosity model for high reynolds number turbulent flows. Computers \& Fluids. 1995;24:227-38.

[195] Wilcox DC. Reassessment of the scale-determining equation for advanced turbulence models. AIAA Journal. 1988;26:1299-310.

[196] Frisch U, Kolmogorov AN. Turbulence: The Legacy of A. N. Kolmogorov: Cambridge University Press; 1995.

[197] Birnir B. The Kolmogorov-Obukhov Theory of Turbulence: A Mathematical Theory of Turbulence: Springer New York; 2013.

[198] Secchiaroli A, Ricci R, Montelpare S, D'Alessandro V. Numerical simulation of turbulent flow in a Ranque-Hilsch vortex tube. International Journal of Heat and Mass Transfer. 2009;52:5496-511.

[199] Ridluan A, Eiamsa-ard S, Promvonge P. Numerical simulation of 3D turbulent isothermal flow in a vortex combustor. International Communications in Heat and Mass Transfer. 2007;34:860-9.

[200] Eiamsa-ard S, Promvonge P. Numerical investigation of the thermal separation in a Ranque-Hilsch vortex tube. International Journal of Heat and Mass Transfer. 2007;50:821-32.

[201] Jochmann P, Sinigersky A, Hehle M, Schløfer O, Koch R, Bauer HJ. Numerical simulation of a precessing vortex breakdown. International Journal of Heat and Fluid Flow. 2006;27:192-203.

[202] Al-Ajmi RM, Syred N, Bowen P, Khalatov A, Al-Shaghdari MA. A comparison of CFD and LDA studies of internal vortex cooling systems for turbine blades. Journal of Flow Visualization and Image Processing. 1998;5:197-210.

[203] Zhang J, Nieh S. Simulation of gaseous combustion and heat transfer in a vortex combustor. Numerical Heat Transfer; Part A: Applications. 1997;32:697-713.

[204] Sampath S, Ganesan V. k- epsilon MODEL IN TWO-DIMENSIONAL RECIRCULATING FLOWS. In: Veziroglu TN, editor. Miami, FL, USA: Univ of Miami; 1982. p. 172-4. 
[205] Przekwas AJ, Singhal AK, Tam LT. Modeling of two-phase reactive flows in swirl combustion chambers. 1983.

[206] Saqr KM, Wahid MA. Effects of Swirl Intensity on Heat Transfer and Entropy Generation in Turbulent Decaying Swirl Flow. Applied Thermal Engineering. 2014;70:486-93.

[207] Radwan A, Ibrahim KA, Hanafy A, Saqr KM. On RANS Modeling of Unconfined Swirl Flow. CFD Letters. 2014;6:159-74.

[208] Saqr KM, Kassem HI, Aly HS, Wahid MA. Computational study of decaying annular vortex flow using the $R \varepsilon / k-\varepsilon$ turbulence model. Applied Mathematical Modelling. 2012;36:4652-64.

[209] Saqr KM, Aly HS, Kassem HI, Sies MM, Wahid MA. Computations of shear driven vortex flow in a cylindrical cavity using a modified $\mathrm{k}-\varepsilon$ turbulence model. International Communications in Heat and Mass Transfer. 2010;37:1072-7.

[210] Sagaut P. Large Eddy Simulation for Incompressible Flows. Third ed. Berlin Heidelberg New York: Springer; 2005.

[211] LESIEUR M. Turbulence in Fluids. Fourth ed: Springer,; 2008.

[212] Tsinober A. An Informal Conceptual Introduction to Turbulence. Second Edition of An Informal Introduction to Turbulence ed: Springer; 2009.

[213] Pozrikidis C. Fluid Dynamics - Theory, Computations and numerical Simulation. Second ed. USA: springer; 2009.

[214] Hoffmann KA, Chiang ST. Computational Fluid Dynamics Volume 1. Fourth ed. USA: A Publication of Engineering Eeducation System; 2000.

[215] Hoffmann KA, Chiang ST. Computational Fluid Dynamics Volume 2. Fourth ed. USA: A Publication of Engineering Eeducation System; 2000.

[216] Speziale CG, Abid R, Anderson EC. Critical evaluation of two-equation models for near-wall turbulence. AIAA Journal. 1992;30:324-31.

[217] Ekaterinaris JA, Menter FR. Computation of oscillating airfoil flows with one- and two-equation turbulence models. AIAA Journal. 1994;32:2359-65.

[218] Wilcox DC. Comparison of two-equation turbulence models for boundary layers with pressure gradient. AIAA Journal. 1993;31:1414-21.

[219] Menter FR. Two-equation eddy-viscosity turbulence models for engineering applications. AIAA Journal. 1994;32:1598-605.

[220] N. Rostamzadeh RMK, B.B. Dally, Z.F. Tian. An Experimental and Computational Study of Flow over a NACA 0021 Airfoil with Wavy Leading Edge Modification. 18th australian fluid mechanics conference. Australia2012.

[221] Starzmann R, Carolus T. Model-Based Selection of Full-Scale Wells Turbines for Ocean Wave Energy Conversion and Prediction of their Aerodynamic and Acoustic Performances. Proceedings of the Institution of Mechanical Engineers, Part A: Journal of Power and Energy. 2013;228:2-16.

[222] Halder P, Samad A, Kim J-H, Choi Y-S. High performance ocean energy harvesting turbine design-A new casing treatment scheme. Energy. 2015;86:219-31.

[223] Halder P, Samad A. Wave Energy Harvesting Turbine: Performance Enhancement. Procedia Engineering. 2015;116:97-102.

[224] Ghisu T, Puddu P, Cambuli F. Numerical analysis of a wells turbine at different non-dimensional piston frequencies. Journal of Thermal Science. 2015;24:535-43.

[225] Halder P, Samad A. Casing Treatment of a Wave Energy Extracting Turbine. Aquatic Procedia. 2015;4:516-21.

[226] Setoguchi T, Kaneko K, Hamakawa H, Inoue M. Measurement of hysteresis on wells turbine characteristics in reciprocating flow. the First International Symposium on Experimental and Computational Aerothermodynamics of Internal Flows1990. p. 537-43. 
1 [227] Takao M., Nagata S., Setoguchi T., K. T. A study on the effects of blade profile and non-uniform tip 2 clearance of the Wells turbine. the ASME 27th international conference on offshore mechanics and 3 arctic engineering, OMAE2008 2008 p. 1-8.

4 [228] Torresi M, Camporeale S, Pascazio G. Performance of a Small Prototype of a High Solidity Wells 5 Turbine. Seventh European Conference on Turbomachinery Fluid Dynamics and Thermodynamics.

6 Athens, Greece 2007.

7 [229] Torresi M, Camporeale S, Pascazio G. Experimental and Numerical Investigation on the

8 Performance of a Wells Turbine Prototype. Seventh European Wave and Tidal Energy Conference.

9 Porto, Portugal 2007.

10 [230] Swaminathan G. Performances and flow investigations on Wells turbine [PhD]: IIT Madras; 1990.

11 [231] Raghunathan SO, OO. The Wells turbine in an oscillating flow. 19th intersociety energy conversion 12 engineering conference San Francisco1984.

13 [232] Puddu P, Paderi M, Manca C. Aerodynamic Characterization of a Wells Turbine under Bi-

14 directional Airflow. Energy Procedia. 2014;45:278-87.

15

16 